\title{
Possible energy futures for Brazil and Latin America in conservative and stringent mitigation pathways up to 2050
}

\author{
Sara Herreras Martínez ${ }^{\mathrm{a}, *}$, Alexandre Koberle ${ }^{\mathrm{b}, \mathrm{d}}$, Pedro Rochedo ${ }^{\mathrm{b}}$, Roberto Schaeffer ${ }^{\mathrm{b}}$, \\ Andre Lucena ${ }^{\mathrm{b}}$, Alexandre Szklo ${ }^{\mathrm{b}}$, Shuichi Ashina ${ }^{\mathrm{c}}$, Detlef P. van Vuuren ${ }^{\mathrm{a}, \mathrm{d}}$ \\ a Copernicus Institute of Sustainable Development, Utrecht University, Heidelberglaan 2, NL-3584 CS Utrecht, The Netherlands \\ b COPPE, Universidade Federal do Rio de Janeiro, Centro de Tecnologia, Bloco C, Sala 211, Cidade Universitária, Ilha do Fundão, 21941-972 Rio de Janeiro, RJ, Brazil \\ c National Institute for Environmental Studies, Onogawa 16-2, Tsukuba, Ibaraki 305-8506, Japan \\ d PBL Netherlands Environment Assessment Agency, PO Box 303, 3720 BA Bilthoven, The Netherlands
}

\section{A R T I C L E I N F O}

\section{Article history:}

Received 11 July 2014

Received in revised form 29 April 2015

Accepted 7 May 2015

Available online 29 May 2015

\section{Keywords:}

Latin America

Brazil

Climate change

Emissions

Integrated assessment models

Climate policies

\begin{abstract}
A B S T R A C T
Latin America has a unique position to address climate change impacts due to its many mitigation opportunities and its growing economy. This paper applied two global and one regional integrated assessment models to assess the energy and emissions trends in Brazil and the rest of the Latin American region up to 2050 based on a set of scenarios consistent with current trends and with the $2{ }^{\circ} \mathrm{C}$ global mitigation target. The models show that to achieve this target, deep $\mathrm{CO}_{2}$ emission reductions are needed. The power sector offers the greatest mitigation opportunities. The implementation of CCS, in combination with fossil fuels and bioenergy, and hydro, biomass and wind energy are identified in this study as the most promising low-carbon options for the region. The realistic implementation of these options will depend, however, on their capability to overcome the present technical, economic, environmental and social challenges. Besides, an appropriate policy framework to stimulate the transformation of the energy system is also important. Brazil is the first country in Latin America to adopt a national voluntary mitigation goal by law. However, the assessment of the effectiveness of this goal up to now becomes difficult due to the vague targets established.
\end{abstract}

(C) 2015 Elsevier Inc. All rights reserved.

\section{Introduction}

The global energy system faces several key challenges, related to securing sufficient supply to support economic development, limiting energy security issues and mitigating the environmental impacts. Climate change represents a crucial challenge in this context: in order to limit global warming to less than $2{ }^{\circ} \mathrm{C}$ compared to pre-industrial levels (consistent with the Cancun Agreements), greenhouse gas emissions associated with energy use need to be reduced all around the world. To understand global response strategies better, it is important to look at regional trends. While several studies have looked at trends in Asian regions (Calvin et al., 2012; Johansson et al., 2014; Lucas

\footnotetext{
* Corresponding author. Tel.: + 31302532404.

E-mail address: saraherreras@gmail.com (S. Herreras Martínez).
}

et al., 2013; van Ruijven et al., 2012), much less studies have looked at trends in the Latin American (LAM) region. LAM is on the one hand vulnerable to climate change, given the key role of natural systems (IPCC, 2014a; R. Schaeffer et al., 2013), but it also has a unique position in addressing the issue. Many countries in the region may profit in their response strategies from the abundance of natural resources and their growing economies. With this in mind, several countries have elaborated low-carbon plans: e.g., Brazil, Colombia, Mexico, Bolivia, Chile, Costa Rica, and Peru. Brazil, in particular, has an important position in mitigation initiatives worldwide, launching comprehensive programs such as the National Plan on Climate Change (Ministry of Environment Brazil, 2007).

In 2010 the LAM region accounted for about $11 \%$ of global greenhouse gas (GHG) emissions (Vergara et al., 2013b). Interestingly, the 2010 emissions were about 11\% below the 
2000 emissions, largely caused by a decline in land-use (LU) related emissions. The latest IPCC report showed the LAM region among those with the highest abatement potential across different scenarios (IPCC, 2014b). The great mitigation potential of the region is attracting interest among the international community to explore low-carbon development opportunities further (de la Torre et al., 2009; IADB, 2013; IEA, 2013; Vergara et al., 2013a,b). However, only a limited amount of studies have assessed and quantified the implications of high and low mitigation commitments in the long-term in the LAM region, in general, or in Brazil in particular, often using very different assumptions (Borba et al., 2012; IEA, 2013; IPCC, 2007a; La Rovere et al., 2013; Nogueira et al., 2014a; Vergara et al., 2013a,b).

This study aims to address the current lack of scenario analysis in LAM by looking into a set of long-term pathways developed by three different integrated assessment models (IAMs) for Brazil and the rest of LAM region (henceforth referred to as RLAM). The use of multiple models allows a better assessment of the uncertainties involved and has been a major tool in exploring the role of different technologies over time under various assumptions such as climate policy or different socio-economic developments (Eom et al., 2013; Grübler et al., 2007; Kriegler et al., 2014b; Riahi et al., 2013; M. Schaeffer et al., 2013). This paper, in particular, explores the potential development of the energy sector and its emissions with and without stringent climate policy. By doing this, the study addresses the following questions:

1) How does the future for the energy system and $\mathrm{CO}_{2}$ emissions look like in Brazil and the RLAM in these scenarios?

2) What are the key challenges to implement the required mitigation strategies in LAM, according to the models?

3) How do the identified mitigation pathways, according to the models, compare to current policies in Brazil?

The article is structured as follows. Section 2 describes the methodology and the input data used. Section 3 presents the results for a variety of variables from the models utilized in the analysis. Section 4 discusses the outcomes, the limitations of the study and how the main findings relate to the challenges faced by the region as well as to the climate policy context in Brazil. Finally, Section 5 presents the conclusions.

\section{Methodology}

\subsection{Model description}

This paper employs the results of two global IAMs (IMAGE and AIM-Enduse) and one regional IAM (MESSAGE-Brazil) to assess possible emissions pathways up to 2050 in Brazil and the RLAM (including the Caribbean and Mexico). Comparing the global projections with national insight provides a better understanding of the implications of climate change and energy responses at more refined scales, improving the quality of projections. The models are used for the development of a set of future climate scenarios. Each model uses different approaches including partial equilibrium, techno-economic and hybrid approaches. The diversity of approaches is important since it allows understanding structural uncertainties among the models as well as identifying which findings are more robust across the various methodologies. The models also differ with respect to the representation of greenhouse gas emissions, sectors and the timeframe (Table 1 ). A short description of the participating models is presented below. For further technical description of the models, see Appendixes A, B and C.

The Integrated Model to Assess the Global Environment (IMAGE 2.4) framework (Bouwman et al., 2006), developed by the Netherlands Environmental Assessment Agency, consists of a set of linked and integrated models that describe fundamental elements in the long-term dynamics of global environmental change, such as air pollution, land-use change and climate change. The main components are the global energy model TIMER 2.0 (Bouwman et al., 2006), the land use and the land cover submodel and the climate policy model FAIR-SiMCaP (Den Elzen and Lucas, 2005). The energy model TIMER describes the demand and supply of 12 different energy carriers for 26 world regions. The IMAGE land-cover submodels simulate the change in land use and land cover driven by demands for food, timber and biofuels and changes in climate. The FAIR module distributes the global emission reduction across the different regions, gases and sources in a cost-optimal manner by using information on marginal abatement costs. The SiMCaP pathfinder module uses an iterative procedure to find multi-gas emission paths that correspond to a pre-defined climate target (Van Vuuren et al., 2007).

The AIM-Enduse model (Asia-Pacific Integrated Model) is an inter-temporal dynamic optimization, techno-economic model for mid- to long-term climate policy assessment. The world is divided into 32 regions over a time horizon up to 2050 and covers both the energy and non-energy sectors (e.g., agriculture, waste, and fluorinated gases) (Kainuma et al., 2003a, 2013). It simulates flows of energy and materials in an economy, from supply of primary energy and materials, to conversion and supply of secondary energy and materials and to satisfaction of end-use services. AIM-Enduse models these flows of energy and materials through detailed representation of technologies. Consequent emissions are modeled elaborately. Selection of technologies takes place in a linear optimization framework where system cost is minimized based on the exogenously given energy price under several constraints like satisfaction of service demands, availability of energy and material supplies, and limiting GHG emissions to a specific level.

MESSAGE is a perfect-foresight, mixed integer linear optimization model developed by the International Institute for Applied Systems Analysis (IIASA) and the International Atomic Energy Agency (IAEA) to evaluate alternative energy supply options under economic, environmental or technical constraints, among others. MESSAGE-Brazil (MSG-BR) is a regional variation of the global MESSAGE model developed by the Centre for Energy and Environmental Economics (CENERGIA) of COPPE/UFRJ in Brazil. The Brazilian regional model has been adapted to the Brazilian case with global input variables (e.g., population, GDP, land use, trade) set exogenously; and the country divided into three regions. The current version of MSG-BR was initially developed as part of a study of the IAEA (IAEA, 2006b). Since then, it has been constantly improved to model the Brazilian energy system's adaptation to possible long-term climate change scenarios (de Lucena et al., 2010) and the integration of wind or solar options (Malagueta et al., 2013) into the country's electric power grid. The most recent version includes: fossil fuel power plants with carbon capture and storage (coal and natural gas); improvements to Brazil's petroleum refinery infrastructure 
Table 1

Main characteristics of the participating models in the study.

\begin{tabular}{lllllc}
\hline Model & Scale & Type & Time horizon & Coverage of greenhouse gases \\
\hline IMAGE & Global & $\begin{array}{l}\text { Energy system and land-use partial } \\
\text { equilibrium model }\end{array}$ & Up to 2100 & All GHGs and other radiative agents & Energy and land use system \\
$\begin{array}{l}\text { AIM-Enduse } \\
\text { MESSAGE-Brazil }\end{array}$ & $\begin{array}{l}\text { Global } \\
\text { Regional }\end{array}$ & $\begin{array}{l}\text { Techno-economic model } \\
\text { Hybrid energy system-economic } \\
\text { growth model }\end{array}$ & $\begin{array}{l}\text { Up to 2050 } \\
\text { Up to 2050 }\end{array}$ & $\begin{array}{l}\text { All GHGs and other radiative agents } \\
\mathrm{CO}_{2}\end{array}$ & Energy and land use system \\
Energy system
\end{tabular}

that allow partial flexibility in the runs to naphtha or distillates; an expansion of the advanced liquid biofuel module. The new version also improves the petroleum supply to account for the development of the so-called pre-salt resources in Brazil (Saraiva et al., 2014). For a more complete description of MSG-BR see Nogueira et al. (2014a).

As presented in Table 1, AIM and IMAGE describe both the energy and land-use systems while MSG-BR only describes the energy system. In this paper, we focus mostly on the energy system to include as much as possible all models during the comparison and because LU scenarios are still less robust and need to be further developed before they can be compared with a similar rigor at the regional scale.

\subsection{Model scenarios and assumptions}

The scenarios used in this study were developed in the LIMITS (Low Climate Impact Scenarios and the Implications of Required Tight Emission Control Strategies) project. ${ }^{1,2}$ Further information on the LIMITS project can be found on its website (FEEM, 2014) and in the overview made by Kriegler et al. (2014a). The scenarios describe three possible developments: 1) baseline assumptions, 2) an extension of current policies, and 3) consistent with the $2{ }^{\circ} \mathrm{C}$ target (Table 2).

The baseline scenario addresses the energy and emission developments in the absence of climate policies. The baseline scenario is a counterfeit scenario, unlikely to happen, but it is used here to analyze the consequences of inaction and the net effect of climate policies. This scenario has been used by the IMAGE and AIM models. MSG-BR did not develop a no-policy baseline scenario. The second scenario is a reference-policy scenario $(R e f P o l)$ reflecting a business-as-usual $(B a U)$ trajectory. In the case of AIM and IMAGE the scenario includes current Copenhagen policies and regulations implemented in those regions where they exist, and in MSG-BR, National Appropriate Mitigation Actions (NAMAs) are covered. This scenario is a more representative scenario of the current situation than that of the baseline scenario. Finally, the last scenario studied (450) is a deep mitigation scenario that sets out an energy pathway consistent with limiting the increase in global GHG concentration to

\footnotetext{
1 LIMITS is a model intercomparison study which is part of the European Union Seventh Framework Programme FP7/2007-2013. The LIMITS project assesses plausible outcomes of the Durban Platform negotiations that can be consistent with the objective of keeping global mean warming below $2{ }^{\circ} \mathrm{C}$ since preindustrial levels. It tries to understand what the technological and financial challenges are in achieving a low-carbon world, among other goals.

2 Some updates were made to the LIMITS scenarios for the IMAGE and AIM model results. In IMAGE, an update was implemented to better reflect the current hydropower capacity in Brazil. The changes in hydropower capacity indirectly influenced other parts of the energy system results. In AIM, corrections were introduced to the capacity factor of solar power technologies.
}

$450 \mathrm{ppm} \mathrm{CO}_{2}$-eq. This scenario is consistent with a $70 \%$ chance of meeting the goal of limiting global warming to $2{ }^{\circ} \mathrm{C}$ (IPCC, 2014b). The three possible developments have been evaluated in this paper for the period 2010 to 2050.

The policies that are included in IMAGE and AIM in the RefPol scenario for Brazil and LAM are the regional 2020 targets on emission reductions, renewable portfolio standards and capacity targets (Table 3). Up to 2020 the scenario reflects moderate policy context, and because of this a conservative estimate of the Copenhagen targets has been considered. For example, in the Copenhagen Accord, Brazil promised to reduce 2020 emissions by $36.1-38.9 \%$ compared to BaU levels. For the country, it was assumed that it would actually implement about $50 \%$ of the pledge (18\%). The same approach was used for Mexico. Due to the lack of data for quantitative mitigation targets in the other Latin American countries, the climate targets for Mexico and Brazil were taken as a proxy for the RLAM and a $15 \%$ emission reduction was assumed for this region. The targets included in the RefPol scenario of MSG-BR were based on the NAMAs stated in the 2019 Decennial Energy Plan of Brazil wherever possible. In the Plan, emission reduction ranges are not defined for each sector, but the specific measures to achieve those targets are forced into the model regardless of a baseline. Therefore, energy reduction targets were implemented by reproducing the electricity generation mix, biofuel production/consumption and energy efficiency measures of the 2019 Decennial Energy Plan.

For the $450 \mathrm{ppm}$ scenario, both the AIM and IMAGE models applied a global carbon tax in order to reach the final concentration target. As a result, low cost emission reduction measures in both models were implemented. The MSG-BR model used the regional emission cap of the IMAGE 450 model for Brazil as a constraint.

\subsubsection{Population and income assumptions}

Both, IMAGE and AIM used population assumptions based on the United Nations population prospects (UN, 2009), in which the global population attains 9.2 billion by 2050 . GDP assumptions were taken in both models from the reference scenario of the OECD Environmental Outlook (OECD, 2012). MSG-BR used population data from the Brazilian Institute of Geography and Statistics (IBGE, 2010) and GDP data from the World Energy Outlook (IEA, 2013). ${ }^{3}$ The population and GDP assumptions used by the three models are very similar (Fig. 1). The differences are larger for the GDP in Brazil where the MSGBR model shows more conservative growth rates (Table 4).

\footnotetext{
${ }^{3}$ Economic projections are rather uncertain, certainly for developing countries. Many of the projections of the energy system discussed in the remainder of the manuscript depend on the economic assumptions made by the various studies.
} 
Table 2

Brief description of the three scenarios used in this study.

\begin{tabular}{|c|c|}
\hline Scenario name & Description \\
\hline Baseline & Scenario with no climate policies (only AIM/IMAGE). \\
\hline RefPol (or $\mathrm{BaU}$ ) & $\begin{array}{l}\text { The scenario reflects developments assuming a continuation of current climate policies. In AIM and IMAGE, this scenario } \\
\text { includes the Copenhagen pledges and other expressed policies of individual countries for 2020, which are extended assuming } \\
\text { similar efforts after } 2020 \text { to 2050. In MSG-BR, this scenario includes all the NAMAs for the energy sector defined in the } 2019 \\
\text { Decennial Energy Plan of the country (Ministry of Mines and Energy Brazil, 2010). }\end{array}$ \\
\hline 450 & $\begin{array}{l}\text { This scenario reflects development consistent with a } 450 \mathrm{ppm} \mathrm{CO}_{2} \text {-eq. target. IMAGE and AIM implement this scenario by } \\
\text { assuming a global carbon price. In MSG-BR, instead, a cumulative emission cap was applied for Brazil in the } 2010-2050 \text { period } \\
\text { based on the resulted emissions of the IMAGE global } 450 \text { scenario. }\end{array}$ \\
\hline
\end{tabular}

Compared to historical annual growth rates, according to AIM and IMAGE, Brazil GDP growth is expected to increase in the medium-term, but to decrease the growth rate in the longer term (Table 4). For the RLAM, GDP growth slows down in the entire period of study. Annual population growth rate is anticipated to decline in the medium and long-term for both regions. Annual growth rates on GDP and population for RLAM, especially in the medium-term, are generally slightly higher than those projected for Brazil. The lower population growth in Brazil than in RLAM is a result of historical demographic trends in both regions. Though Brazil in the recent past had a more stable economy with robust monetary and fiscal policies, and relatively low inflation rates compared to the other countries of LAM, this situation is deteriorating as of 2014. On the other hand, Latin American countries such as Peru, Bolivia, Colombia and Chile are experiencing in the last years a much larger economic growth in their economies than that of Brazil, which explains the higher GDP growth projected in RLAM than in Brazil (World Bank, 2012).

\section{Results}

\subsection{Emissions}

\subsection{1. $\mathrm{CO}_{2}$ emissions}

Currently, most of the region's emissions are concentrated in six countries: i.e., Brazil, Mexico, Argentina, Colombia, Peru, Bolivia and Venezuela (de la Torre et al., 2009). Fig. 2 shows the projected total carbon dioxide $\left(\mathrm{CO}_{2}\right)$ emissions from the energy/industry sectors. $\mathrm{CO}_{2}$ emissions are expected to increase over time under the baseline and the RefPol scenario, especially in AIM projections where emission levels in 2050 reach the highest values, $1.7 \mathrm{GtCO}_{2}$ in Brazil and $3.4 \mathrm{GtCO}_{2}$ in the RLAM (Fig. 2). The models project a slightly higher growth rate for Brazil than for the RLAM.

When stringent policies are implemented, IMAGE and MSG-BR project a clear reduction over time compared to 2010 (approximately $1 \%$ to $2 \%$ annual reduction). In contrast, AIM shows an initial decline followed by a small increase after 2040. This increase comes from the allocation of mitigation efforts around the world regions based on marginal costs. In the AIM model most mitigation actions in LAM will be taken before 2040, where emission reductions are more economically feasible than those in other regions. However, from this year onwards, no further mitigation is needed in the region to meet the global $450 \mathrm{ppm}$ target, causing a growth in local emissions. The emission increase projected in AIM after 2040 is also caused by a rapid decline in LU emissions in the region that reduces the need for the energy sector to decrease its emissions (total emissions from energy and land use continues to drop in AIM). Overall, $\mathrm{CO}_{2}$ emissions in Brazil in 2050 in the low-carbon scenario are reduced by $55 \%$ (AIM), 71\% (IMAGE) and 87\% (MSG$\mathrm{BR}$ ) compared to the values of the RefPol scenario. The lower $\mathrm{CO}_{2}$ emission reduction for the energy sector in AIM than that in the other models is also observed in the RLAM, with a reduction of 74\% (IMAGE) and 39\% (AIM) in 2050 compared to the RefPol emissions. These differences between IMAGE and MSG-BR compared to AIM are a consequence of a more prominent role of bioenergy combined with Carbon Capture and Storage (BECCS) and, in the case of the IMAGE model, additional energy intensity improvements. Although models show different levels of emission reduction for the LAM region, they all agree that the emission reductions needed to stay below the $2{ }^{\circ} \mathrm{C}$ target are much larger than those in the commitments made under the Copenhagen agreement.

Table 5 summarizes some of the key characteristics of the emission trends for the RefPol and the 450 scenarios. In the stringent policy scenario, emissions per capita decrease considerably compared to the current policies scenario dropping to an average of $2 \mathrm{tCO}_{2} / \mathrm{cap}$ in LAM. In both regions under the RefPol pathway $\mathrm{CO}_{2}$ emissions peak around 2050, while under the stringent mitigation scenarios such a peak is already reached as early in 2020 (IMAGE/MSG-BR). Annual emission reduction rates in the two regions are around $2 \%$ in the 450 scenario.

$\mathrm{CO}_{2}$ emissions originate both from energy-related activities (e.g., fossil fuel combustion for electricity production and transport) and LU. In Brazil and the RLAM region, the bulk of $\mathrm{CO}_{2}$ emissions currently come from deforestation, driven by agricultural expansion (Fig. 3). This is also reported in other studies (de la Torre et al., 2009). Recently, deforestation rates declined significantly in the region. For example, in the Brazilian Amazon deforestation rates in 2010 were reported to decrease by $67 \%$ since 2004 and 33\% in Central America since the mid1990s (Vergara et al., 2013). However, it is still unclear whether these achievements continued in the most recent years (2012-2013) (INPE, 2013). In the IMAGE model, LU emissions further decline in Brazil over time and even achieve negative values by 2050 as a result of reforestation, mainly driven by a shift of agricultural production from LAM to other regions.

While LU-related emissions are expected to fall significantly, the emission shares of transport, power generation and industry are projected to rise under the $\mathrm{BaU}$ scenario in all models. Power-related emissions are projected to experience the highest growth. IMAGE also projects industry emissions to grow rapidly in both RLAM and Brazil. According to all models, transport emissions will increase significantly in the two regions. The scenarios' outcomes show that transport- and 
Table 3

Copenhagen Accord pledges considered in the RefPol scenario in IMAGE and AIM.

\begin{tabular}{cllll}
\hline Region & $\begin{array}{l}\text { GHG emission reduction targets in } \\
2020 \text { (relative to baseline and } \\
\text { including LULUCF) }\end{array}$ & $\begin{array}{l}\text { Share of renewables in } \\
\text { electricity production }\end{array}$ & $\begin{array}{l}\text { Average GHG emissions intensity } \\
\text { improvements after 2020 (\%/year) }\end{array}$ & Data source \\
\hline Brazil & $36.1 \%$ & N/A & $3.7 \%$ & $\begin{array}{l}\text { Centre for Climate and Energy } \\
\text { Solutions (2011) and GLOBE } \\
\text { International (2013) } \\
\text { Centre for Climate and Energy } \\
\text { Solutions (2011), GLOBE } \\
\text { International (2013), Jotzo (2011) } \\
\text { and UNEP (2010) }\end{array}$ \\
\hline Mexico & $30.0 \%$ & $35 \%$ by 2020 & $3.3 \%$ & \\
\hline
\end{tabular}

a Measured as GHG emissions per GDP at the 2005-market exchange rate.

electricity-related emissions are currently significantly higher in the RLAM region than those in Brazil. This is mostly because hydropower plants and biofuels meet a large part of the final energy consumed in Brazil.

In the 450 scenario, emissions from energy demand and energy supply decrease significantly over time in both regions due to energy efficiency gains and a growing renewable energy sector. IMAGE and AIM project that the largest emission reductions (compared to $B a U$ values) in this scenario in Brazil and in the RLAM occur in the power sector followed by industrial production and transport. MSG-BR shows, however, enormous mitigation potential in the 'other sector' category, which includes sugarcane production (because the sugarcane processing factories can produce sugar in addition to ethanol, it was shifted from the energy sector into the 'other sector' category). The sugarcane-ethanol sector is the largest contributor of emissions in this group. The negative emissions projected by MSG-BR for the 450 scenario under the 'other sector' category are mainly caused by implementing Carbon Capture and Storage (CCS) during the fermentation phase of sugarcane-ethanol. According to MSG-BR, the mitigation potential for BECCS in the ethanol fermentation process is significant and it is expected to be the most economically viable option for CCS in the 450 scenario.

\subsubsection{Non- $\mathrm{CO}_{2}$ emissions}

Although the majority of GHG emissions are $\mathrm{CO}_{2}$ gases, non$\mathrm{CO}_{2}$ gases such as methane $\left(\mathrm{CH}_{4}\right)$, nitrous oxide $\left(\mathrm{N}_{2} \mathrm{O}\right)$ and fluorinated greenhouse gases (F-gases) contribute significantly to climate change (IPCC, 2007b). The present share of non$\mathrm{CO}_{2}$ emissions in Brazil and in the RLAM to the regions' GHG emissions is similar to the global average (20-30\%). Non- $\mathrm{CO}_{2}$ emissions are projected to grow in the baseline and in the RefPol scenario by up to $0.9 \mathrm{GtCO}_{2} \mathrm{e}$ (Brazil) and $1.7 \mathrm{GtCO}_{2} \mathrm{e}$ (RLAM) in IMAGE (Fig. 4). In contrast, the AIM projection shows that non$\mathrm{CO}_{2}$ emissions will only rise in RLAM but will decline after 2010 in Brazil. The difference between the projected trends in the two regions is due to service demand assumptions where the model assumes that non- $\mathrm{CO}_{2}$ emissions from agriculture, livestock and waste grow in the RLAM but not in Brazil.

We see that the emission reduction in the 450 scenario differs by greenhouse gas. While energy-related $\mathrm{CO}_{2}$ gases can be reduced to zero or even achieve negative values by using BECCS, as we have shown previously, non- $\mathrm{CO}_{2}$ emissions in 2050 will only be reduced by 23\% (Brazil) and 30\% (RLAM) from RefPol values according to the models. This causes in IMAGE a more prominent role of non- $\mathrm{CO}_{2}$ gases to total $\mathrm{GHG}$ gases over time (Table 6).

Breaking down non- $\mathrm{CO}_{2}$ emissions by gas, we see that $\mathrm{CH}_{4}$ is the most important gas (around $2 / 3$ of total non- $\mathrm{CO}_{2}$ emissions) followed by $\mathrm{N}_{2} \mathrm{O}$ (Table 6). The most important $\mathrm{CH}_{4}$ emission sources in LAM are the LU sector and the energy supply sector. Agriculture and livestock are the main activities responsible for $\mathrm{CH}_{4}$ emissions from $\mathrm{LU}$ while fossil fuel production (gas and oil) and coal mining are the principal sources of $\mathrm{CH}_{4}$ in the energy supply sector.

The mitigation potential of $\mathrm{CH}_{4}$ is larger than that for the other gases, explained by the high possibilities to reduce emissions in the energy supply sector by improvements in gas flaring and $\mathrm{CH}_{4}$ recovery as well as reducing fossil fuel use. Moreover, as agricultural and the livestock sectors are both very prominent in the Latin American region, additional mitigation
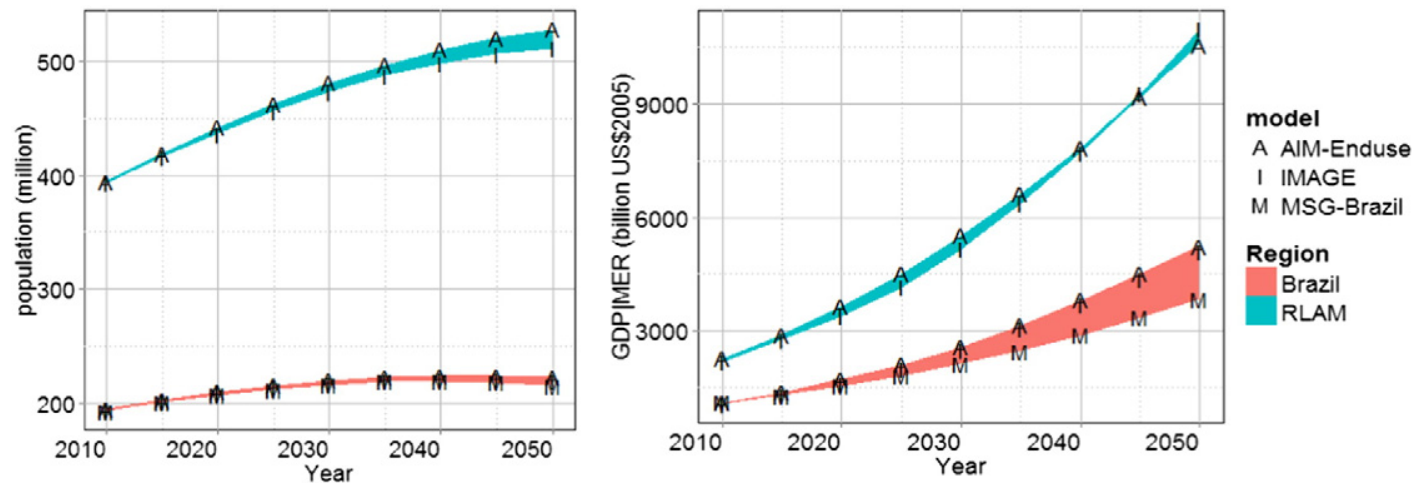

Fig. 1. Total population (left panel) and GDP expressed in year-2005 dollars at market exchange rate (right panel). 
Table 4

Assumptions on GDP and population growth (\%) in the short and medium-terms for the two studied regions.Historical growth rates are calculated based on population and GDP 2000 data taken from UN (2008) and Fresard and Milena (2001), respectively.

\begin{tabular}{|c|c|c|c|c|c|c|c|c|c|c|c|c|}
\hline & \multicolumn{6}{|c|}{ GDP growth } & \multicolumn{6}{|c|}{ Population growth } \\
\hline & \multicolumn{3}{|l|}{ Brazil } & \multicolumn{3}{|l|}{ RLAM } & \multicolumn{3}{|l|}{ Brazil } & \multicolumn{3}{|l|}{ RLAM } \\
\hline & $\begin{array}{l}2000- \\
2010\end{array}$ & $\begin{array}{l}2010- \\
2025\end{array}$ & $\begin{array}{l}2025- \\
2050\end{array}$ & $\begin{array}{l}2000- \\
2010\end{array}$ & $\begin{array}{l}2010- \\
2025\end{array}$ & $\begin{array}{l}2025- \\
2050\end{array}$ & $\begin{array}{l}2000- \\
2010\end{array}$ & $\begin{array}{l}2010- \\
2025\end{array}$ & $\begin{array}{l}2025- \\
2050\end{array}$ & $\begin{array}{l}2000- \\
2010\end{array}$ & $\begin{array}{l}2010- \\
2025\end{array}$ & $\begin{array}{l}2025- \\
2050\end{array}$ \\
\hline AIM & 3.9 & 4.4 & 3.7 & 6.5 & 4.7 & 3.5 & 1.4 & 0.7 & 0.1 & 1.3 & 1.1 & 0.5 \\
\hline IMAGE & 3.9 & 4.3 & 3.9 & 6.0 & 4.4 & 4.0 & 1.4 & 0.6 & 0.1 & 1.2 & 1.0 & 0.5 \\
\hline MSG-BR & 3.9 & 3.4 & 3.1 & & & & 1.4 & 0.6 & 0.1 & & & \\
\hline
\end{tabular}

potential of $\mathrm{CH}_{4}$ emissions could be achieved by other abatement alternatives such as the capture and use of $\mathrm{CH}_{4}$ emissions through anaerobic digesters and animal dietary changes to reduce enteric fermentation emissions.

\subsection{Comparison of emission scenarios with similar studies}

In order to assess the robustness of the outcomes of this study, we compared our scenarios to other scenario studies (Fig. 5). We grouped scenarios into two main groups: current policy scenario (CP) and ambitious policy scenario (AP), comparable to the RefPol and the 450 scenarios respectively. Because no studies were found for the RLAM region, here we look at Brazil and LAM (the whole region). The outcomes show that the scenarios presented here are quite comparable to those found in the literature in terms of total $\mathrm{CO}_{2}$ emissions. Under current policies, most studies expect emissions from energy use in Brazil to keep rising through 2050. In some cases, studies also expect emissions to increase under a stringent policy scenario (World Bank, 2010). Overall, it seems that the scenarios in the literature show slightly deeper emission reductions than those presented here. The projections by the World Bank and in the
World Energy Outlook (IEA, 2013) are the lowest in the range. For the LAM region, similar observations can be made as for Brazil. The regional projections done for Brazil in the CP scenario by the World Bank mainly include the government's own energy expansion plans (Ministry of Mines and Energy Brazil, 2012).

\subsection{Underlying trends in energy use and production}

\subsubsection{Energy use and production trends in Brazil}

The emission trends discussed in the previous section are directly related to underlying trends in energy production and consumption. Fig. 6 (top figure, left half) shows that, in the RefPol scenario, the projections of primary energy consumption in Brazil are fairly consistent across models in the beginning of the studied period (2010 and 2030). Energy consumption increases from around $10 \mathrm{EJ} / \mathrm{year}$ in 2010 to $22-28 \mathrm{EJ} / \mathrm{year}$ in 2050. Both IMAGE and MSG-BR project oil use will fall over time with its share dropping from around $40 \%$ in 2010 to 23\% (IMAGE) and to 27\% (MSG-BR). Natural gas and coal are projected by both models to become important. AIM also projects natural gas to have a more prominent position but the share of coal and oil is kept rather constant over time. The

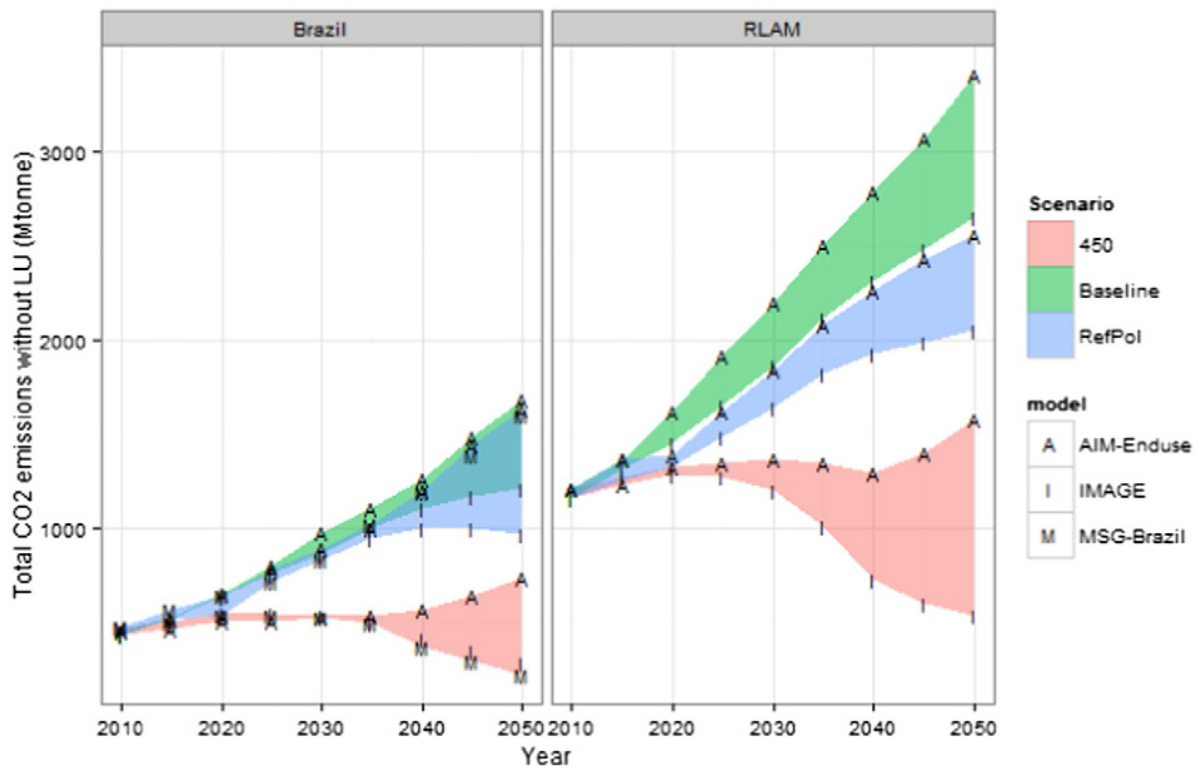

Fig. 2. Total $\mathrm{CO}_{2}$ emissions excluding land-use emissions for Brazil (left panel) and the rest of Latin America (right panel) for the three scenarios. 
Table 5

Overview table of the bandwidth of the models' outcomes for the RefPol and 450 scenarios for Brazil and the rest of Latin America. $\mathrm{CO}_{2}$ emissions do not include land-use related emissions.

\begin{tabular}{lllll}
\hline Variable & Scenario & Unit & Brazil & RLAM \\
\hline Total $\mathrm{CO}_{2}$ emissions & 450 & $\mathrm{MtCO}_{2}$ & $(212-733)$ & $(527-1572)$ \\
in 2050 & RefPol & $\mathrm{MtCO}_{2}$ & $(960-1633)$ & $(2047-2563)$ \\
Per capita $\mathrm{CO}_{2}$ & 450 & $\mathrm{tCO}_{2} / \mathrm{cap}$ & $(1.0-3.3)$ & $(1.0-3.0)$ \\
$\quad$ emissions in 2050 & RefPol & $\mathrm{tCO}_{2} / \mathrm{cap}$ & $(4.4-7.4)$ & $(4.0-4.9)$ \\
$\mathrm{CO}_{2}$ annual & 450 & $\%$ & $(-1.9-1.3)$ & $(-1.9-0.7)$ \\
$\quad$ reduction rate & RefPol & $\%$ & $(2.1-3.3)$ & $(1.4-1.9)$ \\
2010-2050 & & & & \\
Peak year $\mathrm{CO}_{2}$ & 450 & & $2020-2050$ & $2020-2050$ \\
emissions & RefPol & & $2045-2050$ & 2050 \\
\hline
\end{tabular}

models disagree on the contribution of biomass to the energy system in Brazil under the BaU development. AIM shows the contribution of biomass to considerably go down over time whereas in the other two models the share of bioenergy is sustained.

Looking at the 450 scenario, in contrast, we see that IMAGE and AIM project the levels of primary energy of Brazil to be reduced to the RefPol trajectory, especially after 2030 (Fig. 6, below). Under this scenario, Brazil can save up to 3 EJ (AIM) and 6 EJ (IMAGE) by 2050 of primary energy, a drop between $10 \%$ and $28 \%$ of $B a U$ levels. MSG-BR, however, shows a rapid increase in biomass energy, which raises the total primary energy demand by $43 \%$ compared to BaU levels. This result is explained by a shift from coal- and gas- to woody biomasspower plants, which are less efficient (50\%, 33\% and 20\% are the conversion efficiencies assumed for gas, coal and biomass power plants, respectively), leading to an increase in primary energy. In the mitigation scenario of MSG-BR, biomass competes with national and imported coal. Originally, biomass plants using advanced heat and power generation from bagasse, mostly replace domestic coal (that is of low grade and is therefore used inefficiently). Later in the scenario period, bioenergy replaces imported coal, which is more expensive but has larger efficiencies (closer to $40 \%$ ).

Model differences also play a role on the different projected levels of primary energy use in the 450 scenario. In IMAGE, energy efficiency gains are expected to be key to the reduction of energy consumption (Fig. 6, below) while in AIM and MSG$\mathrm{BR}$, energy efficiency is exogenously implemented and does not respond to any price induced effect. Besides differences, the three models show similar developments in the 450 scenario, in particular in the large reduction in fossil fuel use with respect to the RefPol scenario (Fig. 6, below). The energy system begins

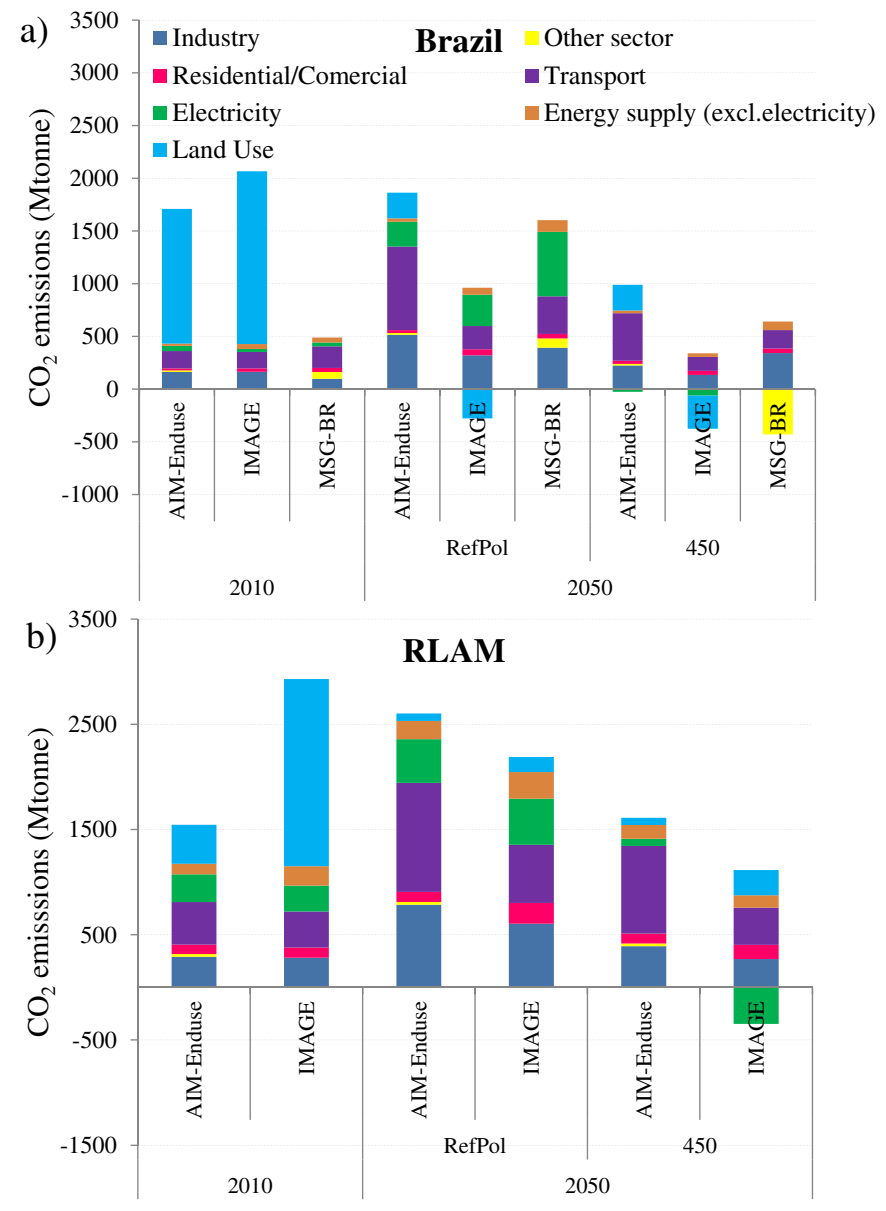

Fig. 3. Sectors contributing to $\mathrm{CO}_{2}$ emissions in 2005 and 2050 in the RefPol and in the 450 scenario in Brazil (panel A) and in the rest of Latin America (panel B). 


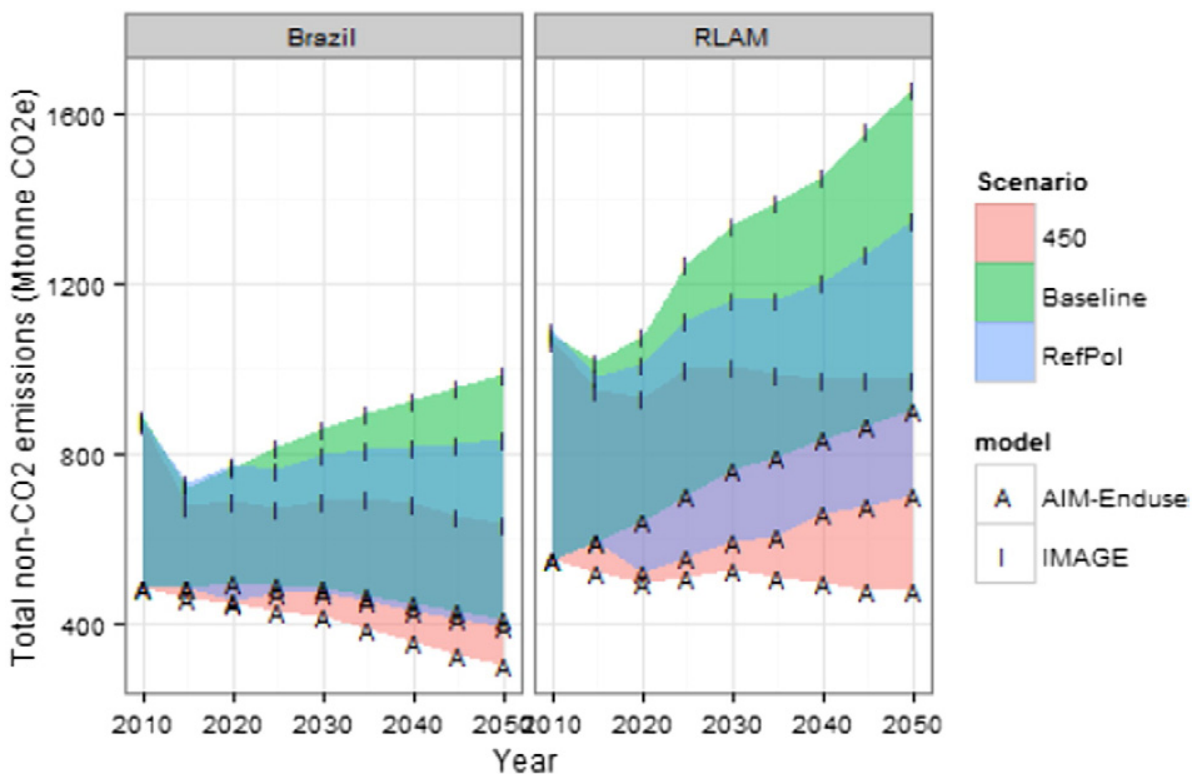

Fig. 4. Total non- $\mathrm{CO}_{2}$ emissions for the three studied scenarios in Brazil (left panel) and the rest of Latin America (right panel). Results are only shown for AIM-Enduse and IMAGE because MSG-BR only reports $\mathrm{CO}_{2}$ emissions.

to rely more on renewable sources as well as on options that include CCS. IMAGE and MSG-BR, for example, show 58\% and $71 \%$ shares of renewable energy sources (hydro, wind, solar and biomass with and without CCS), respectively by 2050 . AIM projects a lower share (46\%). IMAGE and AIM project fossil fuel alternatives combined with CCS to contribute approximately 7 to $9 \%$ to the total primary energy mix by 2050 . The implementation period of CCS technology varies per model and per energy source. MSG-BR expects implementation of BECCS (for sugarcane-ethanol) to start around 2020 while IMAGE and AIM project BECCS' take-off a bit later (2030-2050). All models show that fossil-fuel power plant CCS will be introduced from 2025 onwards.

\subsubsection{Energy use and production trends in RLAM}

In Fig. 7, we can see similar trends for the RLAM as for Brazil. Under the RefPol trajectory, AIM and IMAGE show similar developments, especially up to 2030 . The demand of primary energy is expected to double in this region by 2050 from current levels. According to IMAGE, similar developments for energy demand will occur in the RLAM than in Brazil in the RefPol and in the 450 scenario (approximately 130\% and 70\% growths compared to the current energy levels, respectively). AIM, however, reveals lower growth in energy use in RLAM (30\% lower) than that in Brazil in both scenarios because of the different GDP growths in the two regions.

Oil, gas and biomass will dominate the energy system of the RLAM in the RefPol scenario. As observed for Brazil, oil will also lose some importance in the RLAM region. At the end of the period, a growth of the share of biomass can be noted. IMAGE projects the share of renewables (excluding biomass) to increase faster in the RLAM than that in Brazil in both studied scenarios, mainly due to the expected growth in wind energy.

In the 450 scenario, an increase in renewable energy, CCS and energy efficiency is expected to reduce emissions. The contribution of renewable energy (including biomass) by 2050 constitutes $30 \%$ to $40 \%$ of the total primary energy demand in the region. Options including CCS in combination with gas, biomass and coal will start being implemented in 2035 and will contribute 29\% (IMAGE) and 12\% (AIM) of the primary energy

Table 6

$\mathrm{CH}_{4}, \mathrm{~N}_{2} \mathrm{O}$ and F-gases contribution to non- $\mathrm{CO}_{2}$ gases for Brazil and the rest of Latin America in the baseline and in the 450 scenario. Results are only shown for IMAGE and AIM-Enduse because MSG-BR only reports $\mathrm{CO}_{2}$ emissions.

\begin{tabular}{|c|c|c|c|c|c|c|c|c|c|c|}
\hline \multirow[b]{2}{*}{ Model } & \multirow[b]{2}{*}{ Region } & \multirow[b]{2}{*}{ Scenario } & $\mathrm{CH}_{4}$ & $\mathrm{~N}_{2} \mathrm{O}$ & F-gases & Total non- $\mathrm{CO}_{2}$ gases & $\mathrm{CH}_{4}$ & $\mathrm{~N}_{2} \mathrm{O}$ & F-gases & Total non- $\mathrm{CO}_{2}$ gases \\
\hline & & & \multicolumn{4}{|c|}{2010} & \multicolumn{4}{|l|}{2050} \\
\hline \multirow{4}{*}{ IMAGE } & \multirow{2}{*}{ Brazil } & Baseline & 70.5 & 27.6 & 1.9 & 30.4 & 61.8 & 27.2 & 11.0 & 51.8 \\
\hline & & 450 & 70.3 & 27.8 & 1.9 & 30.1 & 60.2 & 33.2 & 6.5 & 94.1 \\
\hline & \multirow[t]{2}{*}{ RLAM } & Baseline & 72.5 & 24.0 & 3.5 & 28.0 & 61.8 & 19.4 & 18.7 & 37.6 \\
\hline & & 450 & 72.3 & 24.2 & 3.5 & 27.8 & 60.5 & 26.7 & 12.8 & 56.0 \\
\hline \multirow{4}{*}{ AIM-Enduse } & \multirow[t]{2}{*}{ Brazil } & Baseline & 69.1 & 30.0 & 0.9 & 22.0 & 72.9 & 19.0 & 8.2 & 17.7 \\
\hline & & 450 & 69.1 & 30.0 & 0.9 & 22.0 & 67.7 & 22.1 & 10.1 & 23.8 \\
\hline & \multirow[t]{2}{*}{ RLAM } & Baseline & 82.2 & 14.1 & 3.8 & 26.1 & 81.8 & 8.2 & 10.1 & 20.6 \\
\hline & & 450 & 82.2 & 14.1 & 3.8 & 26.1 & 69.2 & 12.0 & 18.8 & 22.7 \\
\hline
\end{tabular}



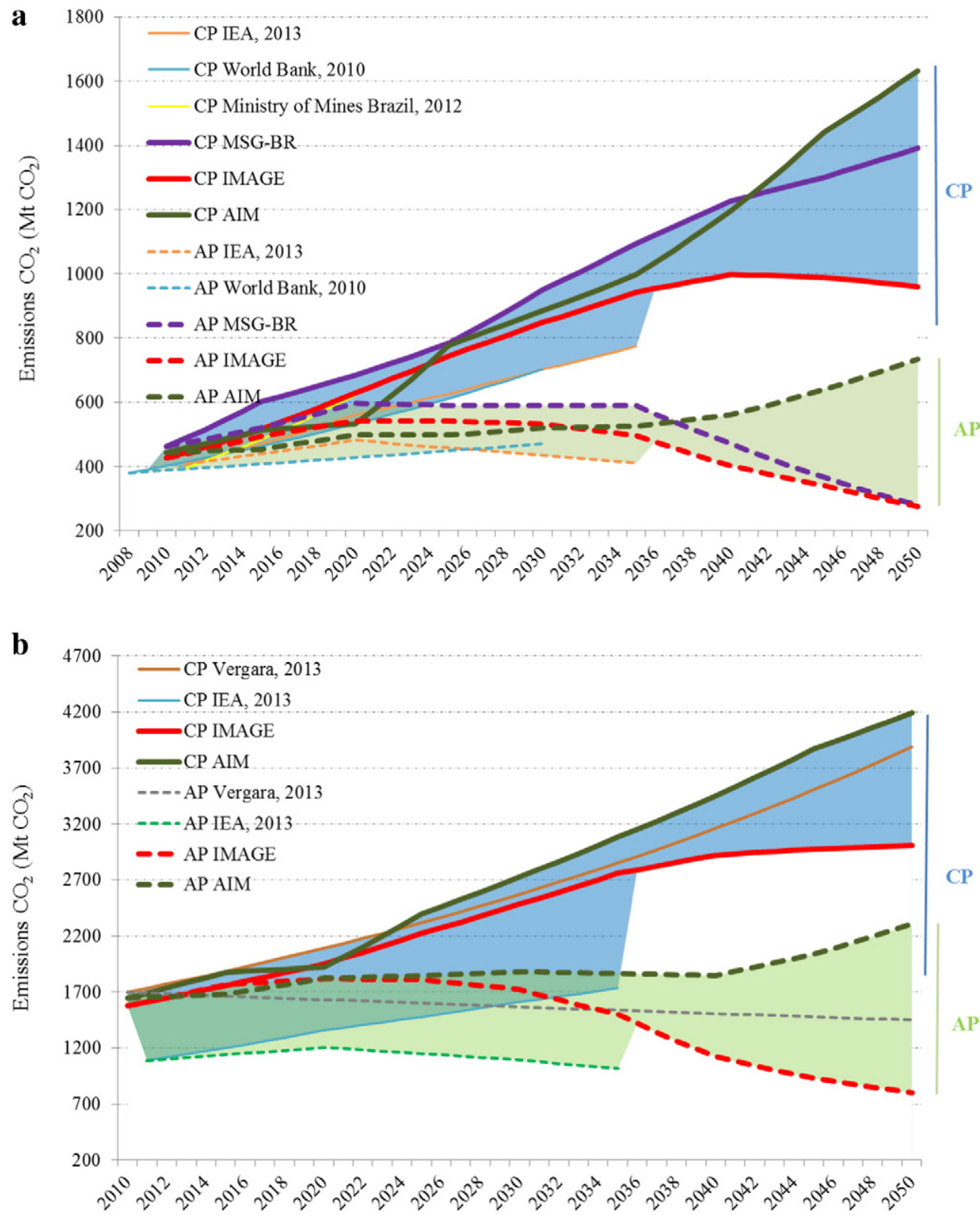

Fig. 5. Comparison of projections of $\mathrm{CO}_{2}$ emissions from energy use in Brazil (panel A) and Latin America (panel B) between our models and other studies in the current policy (CP) scenario and the ambitious policy (AP) scenario.

consumption by 2050 (Fig. 7). The potential for energy efficiency is assessed to be larger in relative terms in RLAM than that in Brazil. This is due to the lower energy-efficient system nowadays in most Latin American countries compared to Brazil, where continued efforts to implement energy-efficiency programs have been made in the last years (Carpio, 2010; IEA, 2013).

The share of renewable energy nowadays in Brazil is above the world's share and significantly higher than that found in other developing economies such as China and India, which are much more based on fossil fuels (Fig. 8). This trend is expected to be held over time. The country also has a significantly higher contribution of renewables compared to the RLAM, a region that is more comparable to other major developing economies. The energy consumption per capita is projected to grow in low-income countries with time and to decrease in the OECD regions.

\subsection{Power sector}

\subsubsection{Power-related emissions and electricity generation}

The power sector is important for deep mitigation pathways because of the large share of this sector in total emissions, and the potential to achieve large emission reductions at lower costs than those in other sectors. Fig. 9 shows (a) the evolution of 

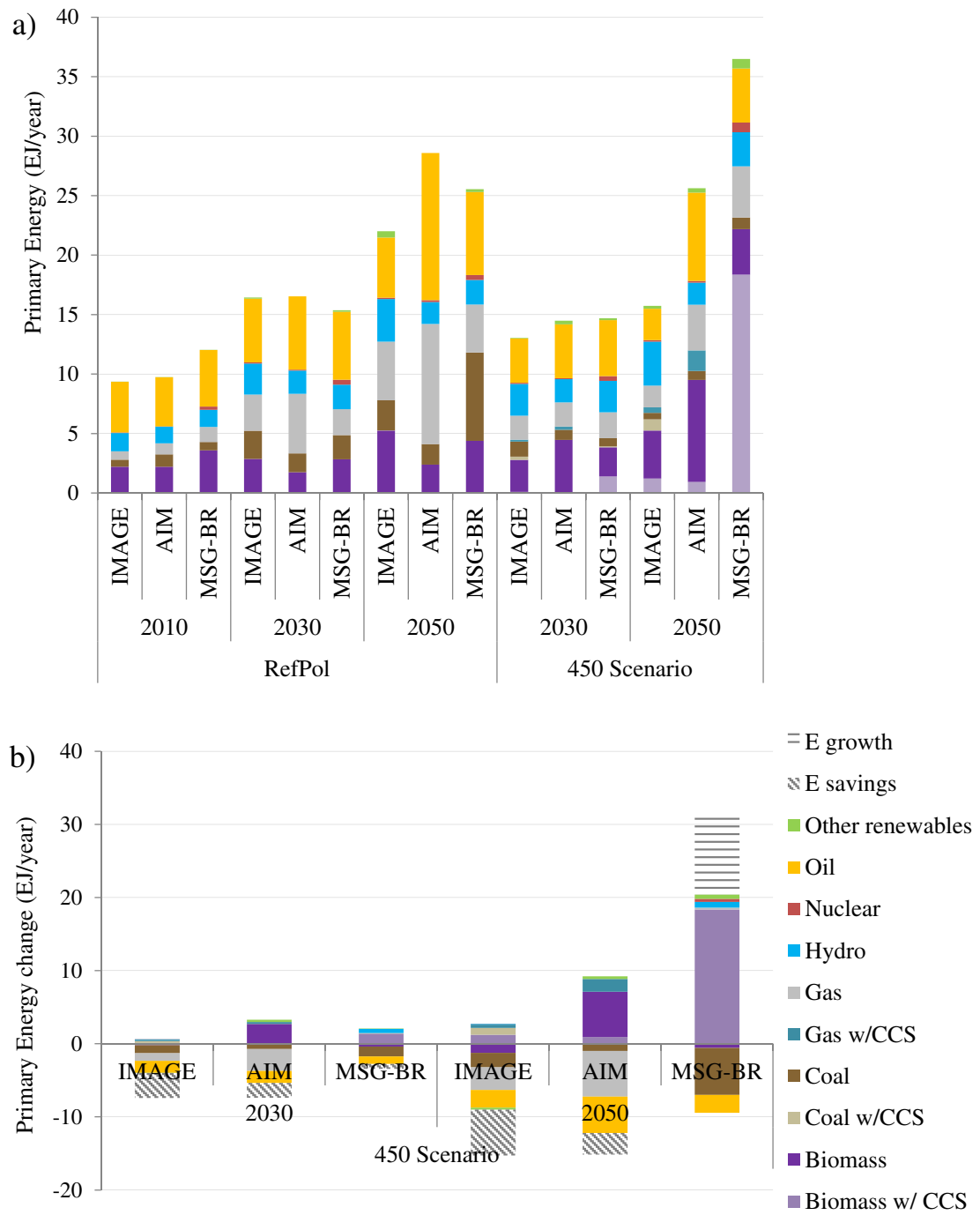

Fig. 6. Primary energy use in 2010, 2030 and 2050 in the RefPol and 450 scenarios (panel A) and primary energy change in the 450 scenario from the RefPol levels in 2030 and 2050 (panel B) in Brazil. Other renewables include solar, wind and geothermal energy. Energy savings are the net difference in the total energy demand.

power $\mathrm{CO}_{2}$ emissions and (b) the mix of electricity production in the RefPol and the 450 scenario in both Brazil (left half of the figure) and RLAM (right half of the figure).

Under the RefPol trajectory, the emissions in the power sector in Brazil projected by IMAGE and MSG-BR in 2050 will continuously grow (according to MSG-BR up to $600 \mathrm{MtCO}_{2}$, a 20 times growth over current levels). AIM, however, projects a much smaller growth. In the RLAM the growth of emissions over time in the RefPol scenario reach beyond $400 \mathrm{MtCO}_{2}$.

Under the 450 scenario, the emissions in the power sector decrease to zero and in the case of IMAGE, to negative values after 2035 in both regions. This represents a reduction of 80$100 \%$ in Brazil and $80-180 \%$ in the RLAM from BaU levels in 2050. The sharp decline is because the models direct most of the biomass use towards the power sector (instead of other sectors such as transport and industry), which generates negative emissions when combining it with CCS technology. Although the largest reduction under the 450 scenario comes from decarbonization, some of the reduction comes from efficiency improvement too.

\subsubsection{Power sector capacity}

Consistent with the trends discussed in the previous section, the power sector capacity needs to grow rapidly in these scenarios (Fig. 10). The largest capacity additions of the three models are projected by IMAGE (3\% annual growth) whereas MSG-BR expectations are much more conservative ( $1 \%$ annual growth). Differences in base year play a key factor here. A peak in capacity is observed around 2030 in AIM results because the model assumes capacity levels, mainly of renewable sources, to increase until 2030 and to slow down afterwards.

Under the low-carbon pathway, the total electrical capacity in 2050 will decline due to energy savings according to IMAGE from the levels of the $B a U$ scenario to $250 \mathrm{GW}$ in Brazil and 

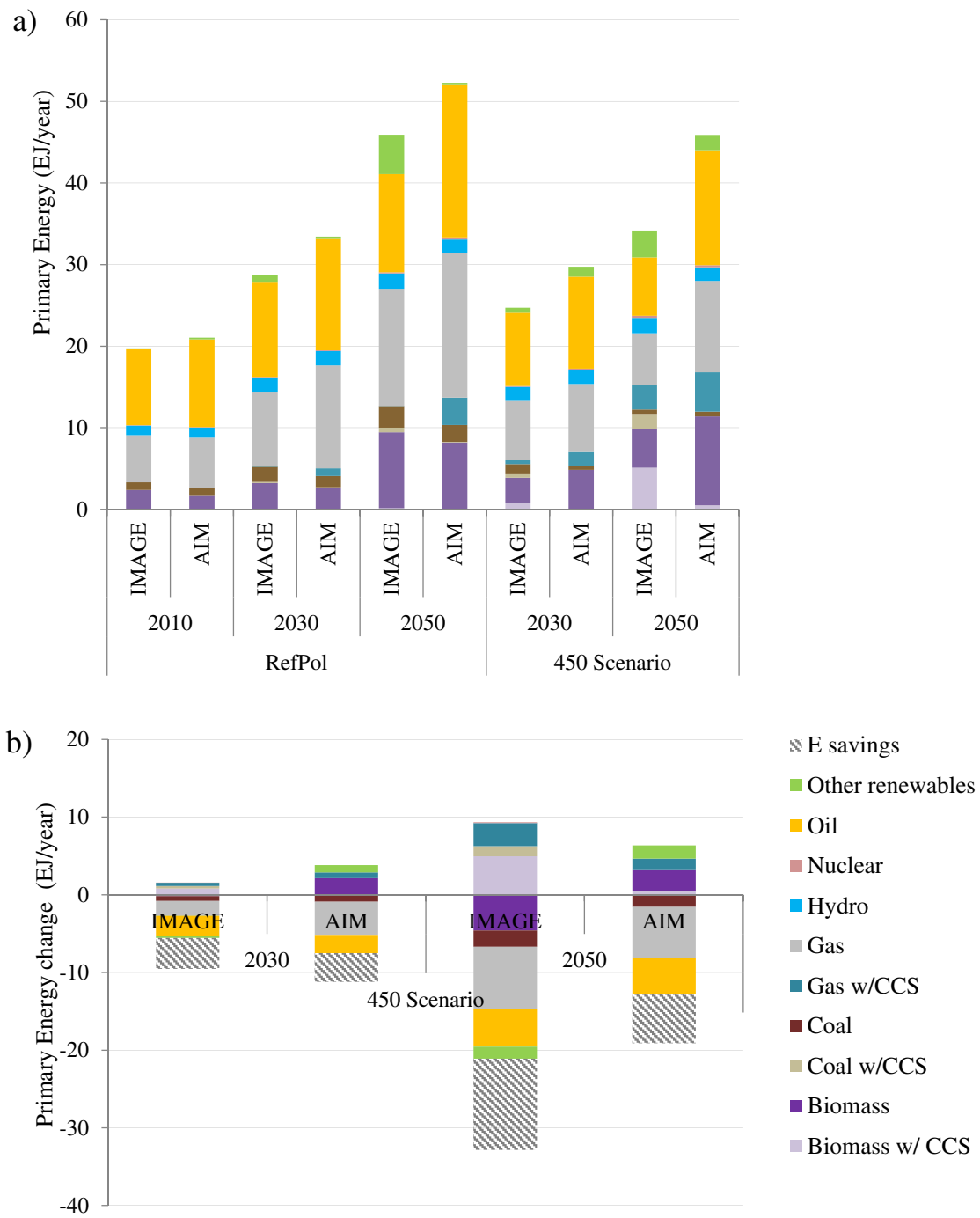

Fig. 7. Primary energy use in 2010, 2030 and 2050 in the RefPol and 450 scenarios (panel A) and primary energy change in the 450 scenario from the RefPol levels in 2030 and 2050 (panel B) in the rest of Latin America. Other renewables include solar, wind and geothermal energy. Energy savings are the net difference in the total energy demand.

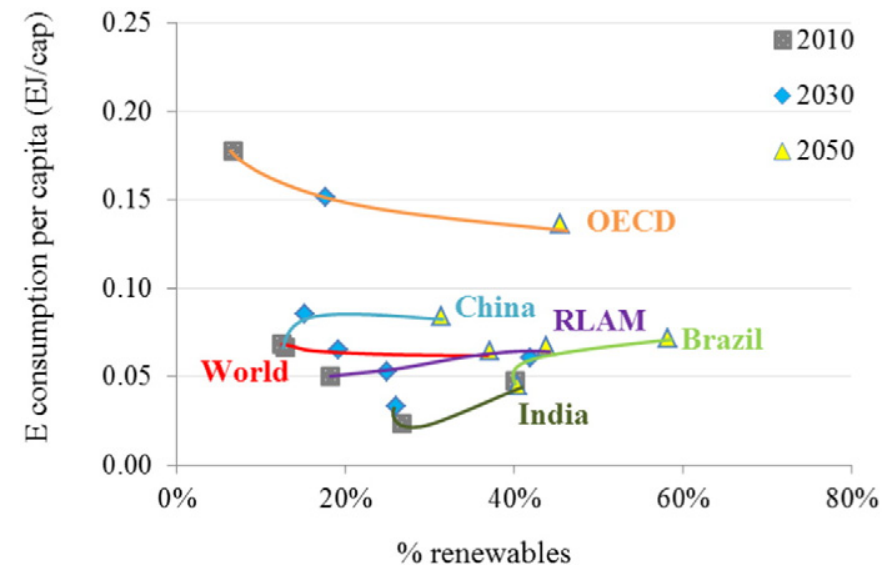

Fig. 8. Energy consumption per capita and contribution of renewables to total energy produced in five world regions in 2010,2030 and 2050 in the 450 scenario. Results are only presented for the IMAGE model because the other two models show similar trends. 

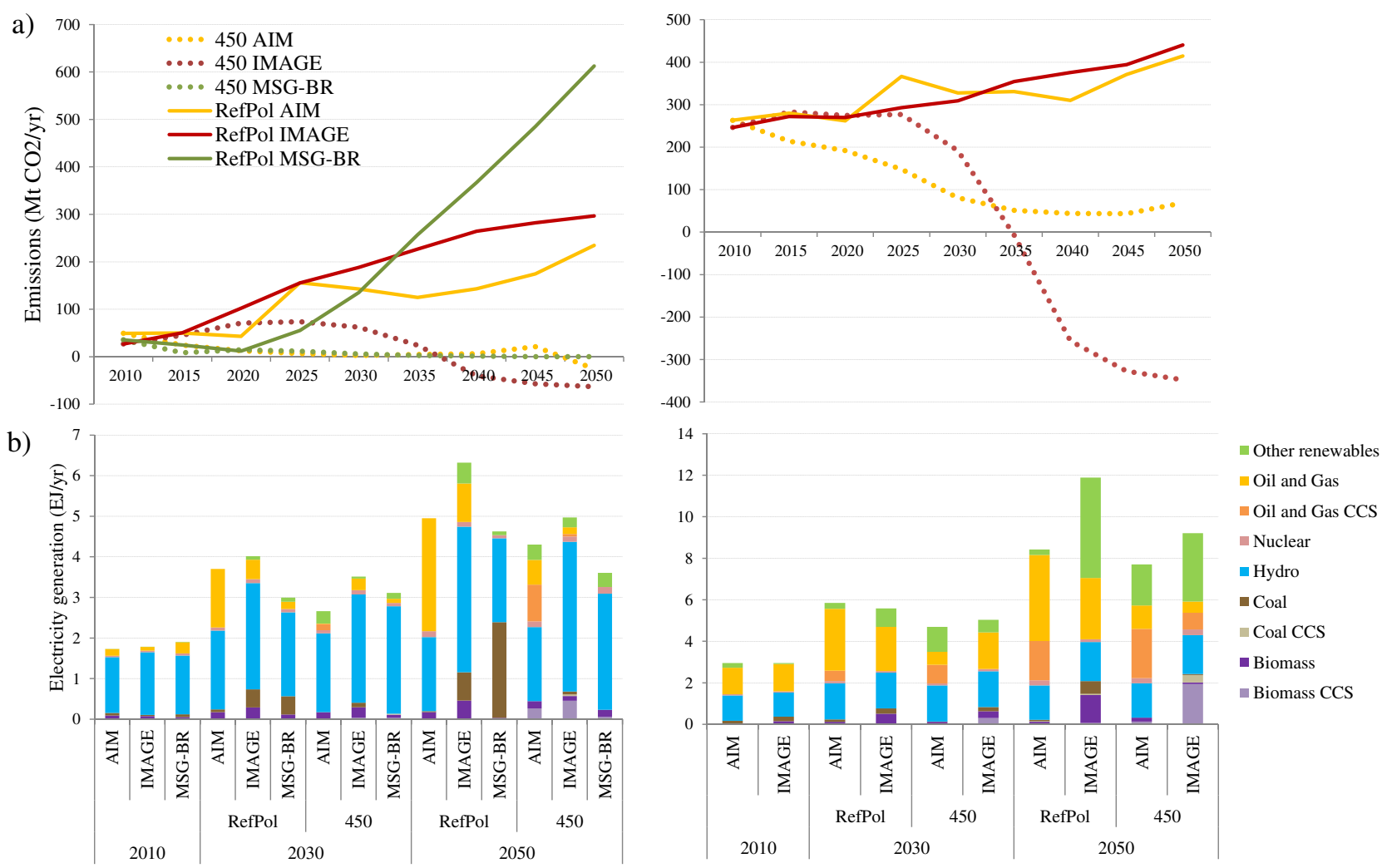

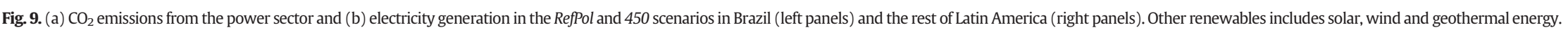



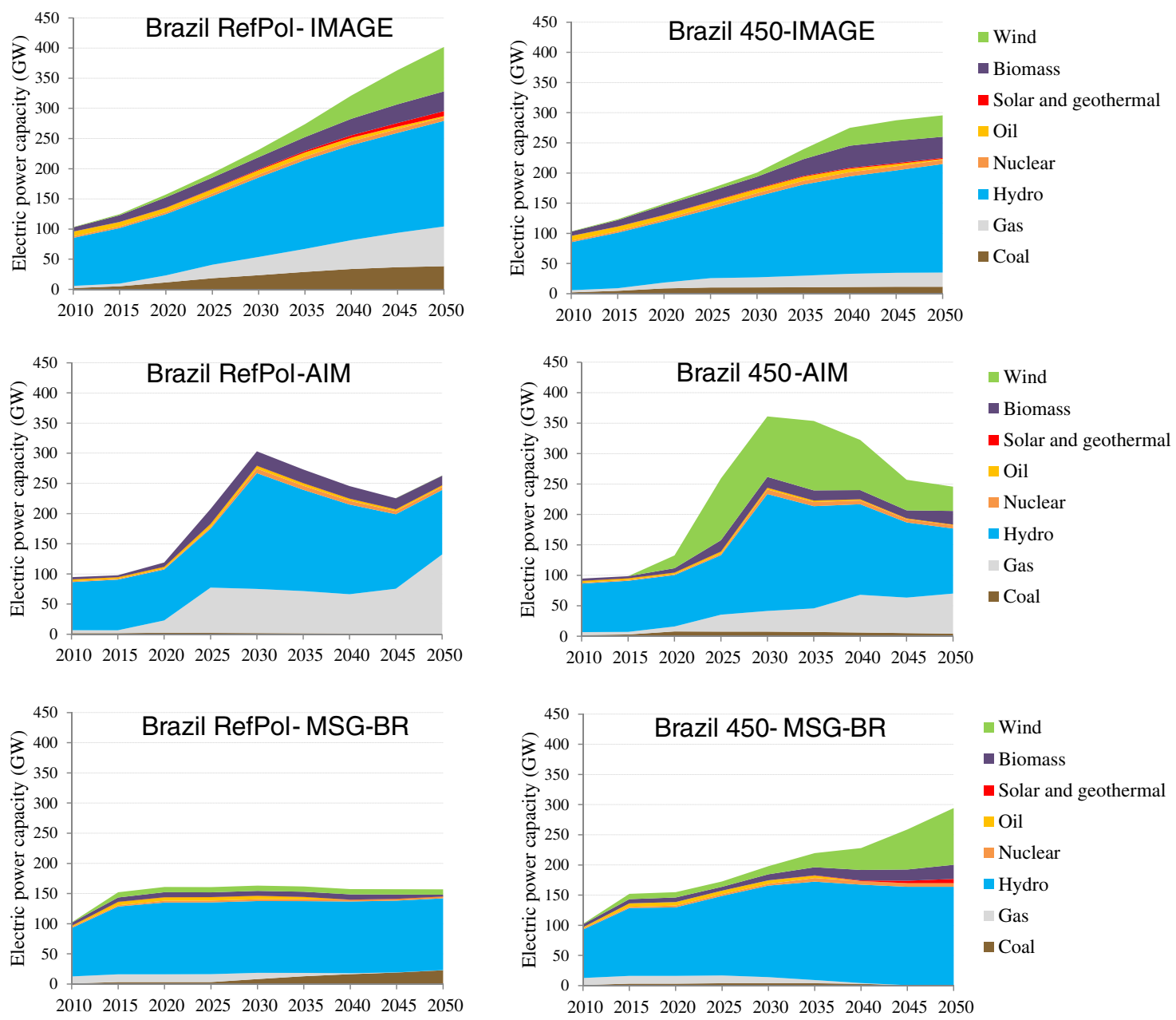

Wind
Biomass
Solar and geothermal
Oil
Nuclear
Hydro
Gas
Coal

Fig. 10. Evolution of electric power capacity in Brazil in the RefPol and 450 scenarios.

700 GW in RLAM (Figs. 10 and 11). The capacity reductions are expected to take place mostly in gas and coal-power plants. A reduction in total capacity, however, is not observed in the power projections made by AIM and MSG-BR because both models consider less energy efficiency improvements. In fact, in MSG-BR the total power capacity in the 450 scenario in 2050 is much higher than that in the RefPol trajectory due to: (i) a lower capacity factor assumed in the model from renewables (50\% for hydro and 30\%-40\% for other renewables) in comparison to coal (85\%) and (ii) the constraints for high levels of intermittent electricity generation that add a flexible power option such as hydro.

The current power sector in Brazil is already low-carbon. Hydropower plants in Brazil remain in the future the main contributor of power capacity in both scenarios. In the mitigation scenario IMAGE, MSG-BR and AIM project an additional capacity of hydroplants of 100, 83 and $27 \mathrm{GW}$, respectively. Only AIM expects hydropower to lose its prominent position due a large growth of natural gas-fired power. In the 450 scenario, the Brazilian power sector is expected to be more diversified as renewables, in particular wind energy and biomass, will also provide a significant amount of the electricity consumed by 2050 .

By zooming in the RLAM region, it can be seen that the projected additional power supply needed in 2050 under the BaU scenario is $350 \mathrm{GW}$ (AIM) and $840 \mathrm{GW}$ (IMAGE), as shown in Fig. 11. While hydropower is also important in the RLAM region, it is not as prominent in Brazil (Sheinbaum et al., 2011). Nevertheless, other renewable sources (in particular wind) are expected to grow more in the RLAM than those in Brazil in both scenarios (IMAGE) and in the 450 scenario (AIM). A rapid growth of gas-fired plans expand under the RefPol scenario is projected but in the 450 scenario, this growth is reduced because of more wind (AIM) and energy-efficiency gains (IMAGE).

\section{Discussion}

\subsection{Limitation of modeling studies and of this study in particular}

We have deliberately included both regional and global models in this study. It is expected that regional models have better access to regional data and can better simulate local 

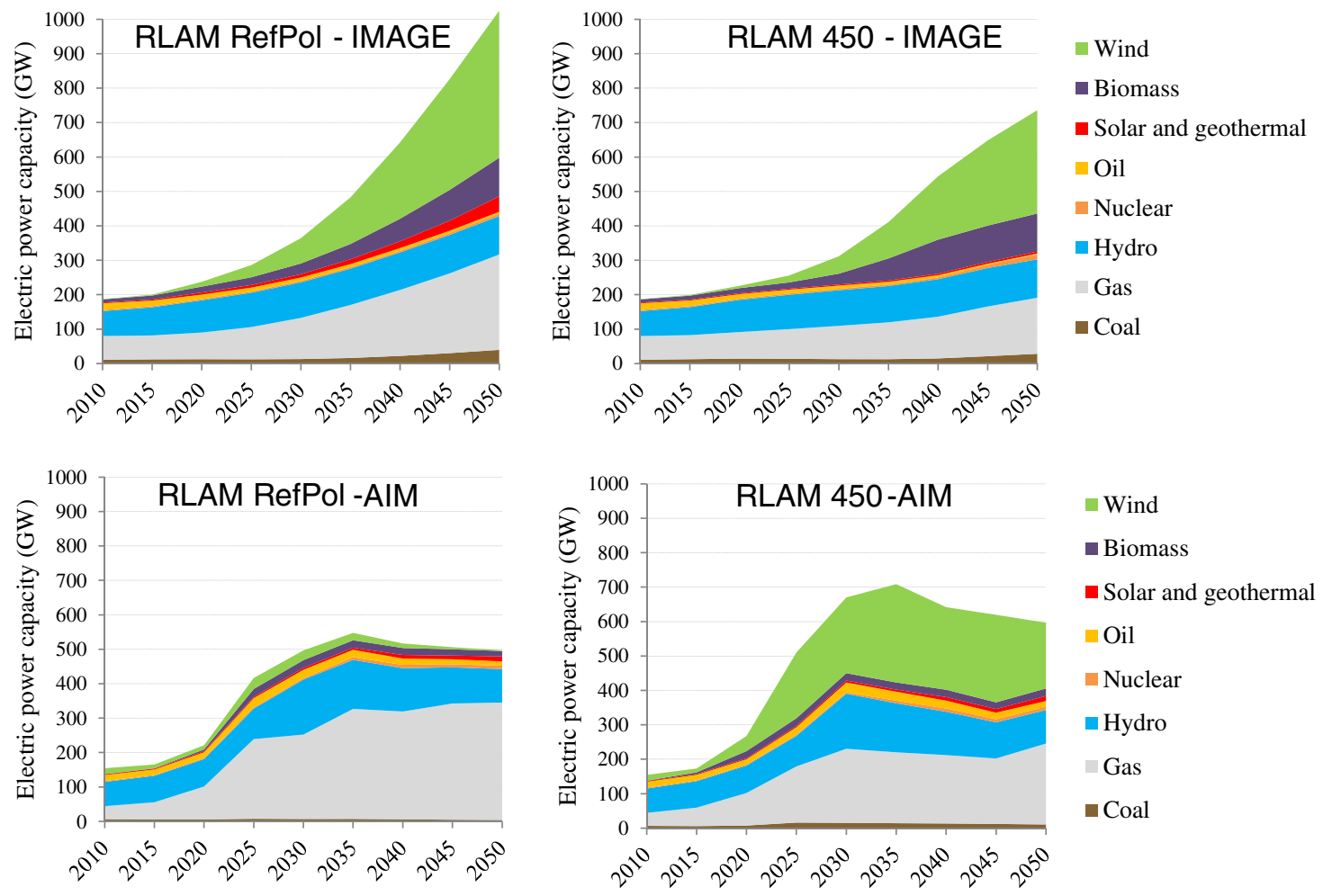

Fig. 11. Evolution of electric power capacity in the rest of Latin America in the RefPol and 450 scenarios.

features than do global models. On the other hand, models at regional scales overlook global effects such as international energy trade and global mitigation actions, which are better covered by global models. Still, the projections of IAMs have clear limitations caused not only by the complex dynamic processes simulated such as demographic and economic development, technological change and climate policies, but also by their underlying assumptions (Schneider, 1997). Some key limitations in the context of this study are:

- Model differences influence the outcomes of the models. While in IMAGE, energy-efficiency gains play a key role on emission mitigation, energy-efficiency in the current version of MSG-BR is set exogenously for the building and the transport sectors. Also in AIM, energy-efficiency only plays a limited role. This may lead to an underestimation of the mitigation capacity of energy-efficiency gains in AIM and MSG-BR projections. In the same way, hydropower, solar and wind are exogenously implemented in IMAGE and AIM but not in MSG-BR. Biomass assumptions in MSG-BR are also different from those in the other two models which leads to a substantially higher share of this energy source under deep mitigation conditions.

- Since the projected capacity of hydropower is exogenously implemented in IMAGE and AIM, for countries, like Brazil, where hydropower plants account for the largest part of domestic electricity generation, this approach is clearly not adequate.
- In the 450 scenario in MSG-BR, the primary BECCS source is the carbon released from the fermentation process during sugarcane-ethanol production, which is the least marginal cost option to output negative carbon emissions in Brazil. As a result, the projected ethanol production exceeds the light duty vehicle fuel demand. In MSG-BR, this is now overcome by allowing the use of ethanol in power generation and in urban buses and cargo transport. In further model improvement, it is important to consider land-use limitations better for sugarcane production, too.

4.2. Putting the main outcomes into perspective: challenges and policy implications

If a $2{ }^{\circ} \mathrm{C}$ global target is to be achieved, the LAM region would also need to work towards mitigation, given the expected emission growth. This will require a rapid transition towards clean energy sources. The implementation of CCS in coal, gas and biomass plants, and the growth of hydro, wind and biomass energy represent promising low-carbon options for the energy system in LAM according to the models' calculation. We briefly discuss how realistic large-scale application of these technologies in Brazil or the RLAM is.

The models identified CCS as a fundamental technology to decarbonize both the industry and the power sectors, partly because it can be attractively combined with bioenergy and fossil fuels. However, to date, there is no commercial CCS application in the power sector or in energy-intensive industries and only a 
handful of large-scale demonstration projects are in operation or under construction worldwide, only one of them in LAM (Santos Basin, Brazil). The implementation of large-scale demonstration projects remains even more complex under the economic and legal contexts of developing and emerging economies (such as LAM) because of its high capital and technology costs and the complexity on its implementation. Given also limitations with storage capacity, water restrictions and societal acceptance, it might be challenging to scale up CCS in LAM as soon as shown in the model outcomes.

Hydropower is already the main source of renewable energy in LAM, supplying over $40 \%$ of total electricity production in most countries and up to $90 \%$ in some countries such as Brazil, Paraguay and almost all Central American countries. The models' results indicate that hydropower is expected to maintain a high share in LAM, especially in Brazil, which is in agreement with Brazil's government expansion plans (Ministry of Mines and Energy Brazil, 2013). The additional capacity projected by some models (100 GW) might be, however, difficult to implement, given the current difficulties to receive environmental licensing or public approval. Any plans to significantly increase hydropower capacity in Brazil will face problems with delays and budget overruns (Tolmasquim, 2012; Viola and Franchini, 2011). There are also indications that climate change may largely affect rainfall patterns in the region increasing concerns over the energy security of hydroenergy (de Lucena et al., 2009).

The present share of wind power in LAM is very low $(0.8 \%$ and 2 GW total installed capacity). Besides Costa Rica, there is no other country with more than $30 \mathrm{MW}$ of wind power installed. However, the Latin American wind power market begins to show more maturity. In 2012, LAM experienced the highest growth rate of wind power investment globally. Cumulative installed capacity in LAM reached 3.5 GW in 2012, an increase of 53\% compared to the $2.3 \mathrm{GW}$ installed in 2011 (Vergara et al., 2013a). The majority of these additions came from large wind farms in Brazil and Mexico. Yet, there are several key issues for the prospects of wind energy in LAM and other regions in the world, such as the transmission of energy from the places of greatest potential to consumption centers and the great costs. The fast growth expected from the models in wind power, growing from $1 \mathrm{GW}$ in 2010 to $230 \mathrm{GW}$ (AIM) and $340 \mathrm{GW}$ (IMAGE) would need to solve these difficulties.

The models agree on the key role of bioenergy in the Latin American region. Biomass resources, mostly from sugarcane or wood, are currently making a significant contribution to the energy supply in some countries (e.g., Brazil, El Salvador, Guatemala, Haiti, Honduras and Nicaragua). In many of these countries, however, a large portion of the biomass used - for either domestic small scale or large-scale industrial purposes has an unquestionable impact on the national forest resources. The sustainability of biomass supply is therefore a clear issue. In IMAGE and AIM, the sustainability criteria are applied to bioenergy supply (e.g., key role for residues, no deforestation allowed), but still in the real world implementing these criteria will be more complicated, as revealed by past trends.

\subsubsection{Climate policies in Brazil in relation to the models' outcomes}

Several countries in the LAM region have recently begun to set the regulatory and fiscal incentives to support low-carbon growth. In general, four main sectors have been chosen by most of the implemented climate policies in the region due to their low costs, their large co-benefits and emission reductions. These are: energy generation, transport, LU and energy efficiency. The main policies supporting low-carbon development in these four sectors for Brazil are discussed.

Since the early 2000 Brazil has introduced climate policies at the national, state and municipality levels. As one of the earliest non-Annex I signatories to the Copenhagen Accord, it has established important climate policies where the most comprehensive is the National Policy on Climate Change (NPCC or PNMC in Portuguese). The NPCC (in force since 2010) established the country's voluntary emission reduction target of 36.1 to $38.9 \%$ by 2020 compared to the 2005 levels. With this, Brazil has become the first country in LAM to adopt a national voluntary mitigation goal by law. Because our model projections focus on $\mathrm{CO}_{2}$ energyrelated emissions, it is not possible to compare the Brazilian target (that includes all GHG) with the outcomes of the study. Other studies have criticized the target to be unambitious and to hardly differ from the baseline (Schaeffer et al., 2010). One issue is that the baseline was revised upwards in the NPCC causing the pledges to be already largely accomplished at the time they were announced (den Elzen et al., 2013). A difficulty in assessing the effectiveness of the Brazilian NPCC is the rather vague target set, which is not always accompanied by the mitigation actions that will accomplish the target.

Even in the presence of these uncertainties, the NPCC is an important framework to mitigate climate change in the country as it incorporates all previous government climate-related instruments (Table 7). Under the NPCC four main objectives were set: (i) reduce GHG emissions from all its sources and to strengthen GHG sinks; (ii) preserve and recuperate national biomes; (iii) reduce climate change vulnerability and increase adaptive capacity work towards adaptation and (iv) develop a national cap-and-trade system. In order to reach the mitigation goals, the NPCC covers areas such as deforestation, energy supply, energy efficiency and transport.

Regarding deforestation, a number of laws and regulations have been adopted. Yet, effective implementation and operation of REDD (Reducing Emissions of Deforestation and Forest Degradation) projects have been challenging due to large competing sectorial incentives and land-tenure issues, among other reasons. Nevertheless, Brazil is currently one of the countries in LAM possessing key capabilities for effective REDD implementation such as technical and human monitoring capacity and good forest management.

Renewable energy is one of the key sectors targeted under the NPCC where the country aims to increase the share of renewable energy to $80 \%$ by 2030 through the expansion of hydropower, bioenergy, wind and solar PV power. Though, since only few concrete measures are included (34 GW of hydropower in 2016 , reduction of power losses by $25 \%$ between 2010 and 2020 and $11.4 \%$ increase of bagasse-sugarcane electricity by 2030), it remains unclear how the target will be met by implementing the individual measures. Comparing this target with the model projections, we can see that the projected share of renewable power for 2030 in the RefPol and 450 scenarios is lower ranging between 57\% (AIM) and 75\% (IMAGE and MSG-BR). In order to achieve this goal, the models expect additional hydro capacity in 2020 to be higher than the targets stated in the NPCC (40 GW and 56 GW in IMAGE and MSG-BR, respectively). 
Table 7

Overview of the main climate policies including in the National Policy on Climate Change of Brazil and their characteristics.Adapted from Nachmany et al. (2014).

\begin{tabular}{|c|c|c|}
\hline Policy (entry year) & Sectors covered & Main characteristics and goals \\
\hline Forest Code (2012) & REDD and LULUCF & $\begin{array}{l}\text { It sets regulation to manage forest, protected areas and water sources } \\
\text { sustainably. Under the Forest Code, which dates back to } 1965 \text {, } \\
\text { landowners must conserve a percentage of their terrain forested, ranging } \\
\text { from } 20 \% \text { in some regions to } 80 \% \text { in the Amazon. }\end{array}$ \\
\hline National Plan on Climate Change (2008) & $\begin{array}{l}\text { Energy supply, energy efficiency, } \\
\text { transport, REDD and LULUCF }\end{array}$ & $\begin{array}{l}\text { The Plan defines actions and measures for climate change mitigation and } \\
\text { adaptation. It aims to increase energy efficiency, the use of renewable power } \\
\text { sources, reduce deforestation, strength adaptation capacity and support climate } \\
\text { change research. }\end{array}$ \\
\hline $\begin{array}{l}\text { Mandatory Biodiesel Requirement } \\
\text { (2005) }\end{array}$ & Transport & $\begin{array}{l}\text { Establishes the mandatory blending of biodiesel to } 5 \% 3 \text { years ahead of the } \\
\text { original schedule (from } 2013 \text { to 2010). }\end{array}$ \\
\hline $\begin{array}{l}\text { Programme for Incentives for Alternative } \\
\text { Electricity Sources - PROINFA (2012) }\end{array}$ & Energy supply & $\begin{array}{l}\text { It sets } 2 \text { targets in two time periods: (1) To have } 3300 \text { MW power } \\
\text { production from renewable sources (wind, biomass and small hydro) by } \\
2007 \text {. This is reached by a system of subsidies and incentives. (2) To } \\
\text { increase the electricity generated by these } 3 \text { power sources to } 10 \% \text { of } \\
\text { annual consumption within } 20 \text { years. During this period, Renewable } \\
\text { Energy Certificates should be issued. }\end{array}$ \\
\hline $\begin{array}{l}\text { National Conservation and Rational } \\
\text { Energy Use Policy (2001) }\end{array}$ & Energy efficiency & $\begin{array}{l}\text { Establishing maximum levels of energy consumption and minimum } \\
\text { levels of energy efficiency for appliances and machines produced and } \\
\text { traded in Brazil. }\end{array}$ \\
\hline
\end{tabular}

As part of the NPCC, Brazil also seeks to decrease electricity consumption by $10 \%$ relative to the baseline in 2030 by energy efficiency actions. This study's projections indicate, conversely, that total consumption of electricity will not be reduced over time in any of the scenarios because of population growth, not even in the long-term. An important barrier to stimulate efficient energy consumption in Brazil is the fossil fuel subsidies, introduced during the 1970s and 1980s when around $80 \%$ of its domestic oil consumption was imported. The subsidy regime reduced incentives for energy conservation and limited the beneficiaries to ethanol producers and the large industrial energy consumers. Although Brazil has now discovered large oil reserves in 2007, the subsidies have not been reformed and they still encourage wasteful consumption. In fact, Petrobras has to buy petroleum distillates and even gasoline in the global market and sell them in Brazil at a loss in order to meet demand (de Oliveira and Laan, 2010). However, removing fossil fuel subsidies is politically complex.

Biomass in combination with CCS offers very interesting prospects to decarbonize the Brazilian energy sector. Although the country does not yet have a legal framework supporting CCS technology, there are a number of research and development programs ongoing. A good example is the Brazilian CCS Network, managed by Petrobras, which established 20 CCS research projects in the country. In addition, the Centre of Excellence in Research and Innovation in Petroleum, Mineral Resources and Carbon Storage (CEPAC), a collaboration between Petrobras and the University of Rio Grande do Sul, is dedicating significant resources to CCS investigation (Beck et al., 2011).

Regarding transport, the NPCC plans an increase of rail and water transport and to improve mass transit, cycling and river cargo. The plan brings forward the $5 \%$ biodiesel blending requirement introduced in 2005 from 2013 to 2010 and seeks the implementation of an international biofuel market.
To ensure an effective enforcement of climate policies, the allocation of climate funds is indispensable. Brazil has the largest budgetary allocation for climate issues in LAM. Within the country's climate change law, specific resources are allocated for the implementation of climate-change policies in the national budget and it has specific climate funds such as the National Climate Change Fund and the Amazon Fund. Besides these funds, a large credit line to support mitigation and adaptation projects was announced in 2012 by BNDES with an estimated budget of US $\$ 570$ million until 2014 , which will be obtained from royalties from the oil industry.

\section{Conclusions}

This study explores the mitigation potential of Brazil and the RLAM up to 2050 under current climate policies and in a scenario limiting global mean temperature increase to $2^{\circ} \mathrm{C}$. The analysis has been based on the results of two global and one regional IAMs. The following conclusions can be drawn from the analysis:

- There is a general agreement between the global and the regional models used in the projected emission trends. Given the current climate policy framework, energy-related $\mathrm{CO}_{2}$ emissions will increase $1.5-3.0 \%$ per year in the whole Latin American region. The models show that in the stringent mitigation scenario, deep $\mathrm{CO}_{2}$ emission reductions are needed from the emissions projected under the commitments in the Copenhagen agreement, ranging between 55\%$87 \%$ in Brazil and $40 \%-74 \%$ in the RLAM. These reductions reveal the urgent need to significantly increase global mitigation efforts if countries really want to achieve this target.

- The power sector is important for deep mitigation pathways because of the large share of the sector in total $\mathrm{CO}_{2}$ emissions and the potential to achieve large emission reductions at 
lower costs than those in other sectors. The power sector offers the largest mitigation opportunities in the pathway consistent with the $2{ }^{\circ} \mathrm{C}$ target, followed by industrial production and transport. MSG-BR also identifies great mitigation potential in Brazil by implementing CCS during the ethanol fermentation process. According to IMAGE, capacity levels in 2050 are reduced from the BaU trajectory to $250 \mathrm{GW}$ (Brazil) and $700 \mathrm{GW}$ (RLAM) due to energy-efficiency gains.

- A large share of clean technologies to the energy demanded in the region is expected under the low-carbon scenario. The implementation of CCS in coal, gas and biomass plants, and the growth of hydro, biomass and wind energy dominate our present view of future low-carbon options in the energy system of LAM. Under the current policy scenario, natural gas (Brazil and RLAM) and coal (Brazil) are dominant sources of primary energy supply in the future but this situation can change if stringent mitigation policies materialize. Our exploration of lowcarbon options suggests that renewables and CCS technologies can provide up to 70\% (Brazil) and 40\% (RLAM) of the energy demanded in 2050. Biomass resources, mostly from sugarcane and wood, remain a key energy source in the region. CCS is a fundamental technology to decarbonize both the power sector and the industry, especially because it can be combined with bioenergy and fossil fuels. In addition, there is a large untapped potential for hydro energy (Brazil and RLAM) and wind energy (RLAM) for power generation.

- Model assumptions play a key role in the models' outcomes for the low-carbon scenario. In IMAGE energy-efficiency gains are expected to be key to the reduction of energy consumption while in the other two models energy-efficiency is exogenously implemented and only minor efficiency improvements are considered. In the same way, projections on hydropower, solar, wind and biomass energy also differ among the models due to the diverse assumptions and implementation approach of these energy sources in each model.

- In order to implement the mitigation options identified, LAM will need to overcome large technical and non-technical challenges. The projected potential for clean technologies in this study can be difficult to realize as it depends not only on technical uncertainties, but also on more elusive issues such as social acceptance and political decisions. All main mitigation options like renewables, CCS and bio-energy face considerable implementation barriers.

- In order to stimulate the transformation of the energy system and increase capacity levels for green energy, the appropriate supportive clean energy policies need to be implemented. Since 2000 Brazil is experiencing a new wave of regulatory changes to stimulate climate change mitigation and renewable energy investment. The country is the first country in LAM to adopt a national emission mitigation target by law under their NPCC framework. However, some studies report the target to be unambitious. A difficulty in assessing the effectiveness of the Brazilian NPCC is the vague targets established, which are not always accompanied by the mitigation actions that will accomplished the target.

\section{Acknowledgments}

The research leading to these results has received funding from the European Union Seventh Framework
Programme FP7/2007-2013 under grant agreement no. 282846 (LIMITS).

\section{Appendix A. Description of the IMAGE model}

The IMAGE 2.4 Integrated Assessment modeling framework consists of a set of coupled models that together describe the key elements of the long-term dynamics such as climate change, land-use change and air pollution (Bouwman et al., 2006). The three main models of the IMAGE framework are TIMER, IMAGE and FAIR. The IMage Energy Regional (TIMER) Model is the energy-system simulation model of IMAGE that describes the demand and supply energy demand of 12 different energy carriers, the related emission of greenhouse gases and regional air pollutants for 26 world regions (Fig. 1). The model also describes land-use demand for energy crops. The steps are connected by demand for energy (from left to right in Fig. A.1) and by feedbacks, mainly in the form of energy prices (from right to left in Fig. A.1). The TIMER model has three types of sub-models: (i) the energy demand model; (ii) models for energy conversion (electricity and hydrogen production) and (iii) models for primary energy supply.

The TIMER model focuses mostly on several dynamic relationships within the energy system such as learning-bydoing, inertia, resource depletion and trade. Because TIMER is a simulation model and not an optimization model, its results depend on a single set of deterministic algorithms instead of being the result of an optimization exercise.The main assumptions within the TIMER model for various energy categories are depicted in Table A.1. The TIMER Emissions Model calculates the regional atmospheric emissions from energy and industryrelated processes. The model covers the following gases: carbon dioxide $\left(\mathrm{CO}_{2}\right)$, methane $\left(\mathrm{CH}_{4}\right)$, nitrous oxide $\left(\mathrm{N}_{2} \mathrm{O}\right)$, nitrogen oxides (NOx), carbon monoxide (CO), non-methane volatile organic compounds (NMVOC), sulfur dioxide $\left(\mathrm{SO}_{2}\right)$ and emissions of halocarbons (CFCs, HCFCs, HFCs, etc.). Emissions are calculated by multiplying primary energy-use flows and industrial activity levels with time-dependent emission coefficients. Changes in these coefficients represent technological improvements and end-of-pipe control techniques for some gases such as $\mathrm{CO}, \mathrm{NMVOC}, \mathrm{NOx}$ and $\mathrm{SO}_{2}$.

The TIMER model is used in combination with the FAIR model and the climate-terrestrial submodel of IMAGE to explore the different emission pathways. The FAIR-SiMCaP 2.0 model is a combination of the abatement costs model of FAIR and the SiMCaP model. The SiMCaP pathfinder module makes use of an iterative procedure to find multi-gas emission paths that correspond to a predefined climate target. The FAIR cost model allocates the necessary global emission reductions by using a least-cost approach and regional MAC curves derived from IMAGE for the different emission sources. Finally, the land and climate modules of IMAGE describe the dynamics of agriculture and natural vegetation, and, together with input from TIMER and FAIR, estimate total emissions, atmospheric concentrations, radiative forcing, and the subsequent climate change. The overall methodology covers three major steps (Fig. A.2):

1. First, the IMAGE and the TIMER models are used for building the baseline emission scenario. These models 


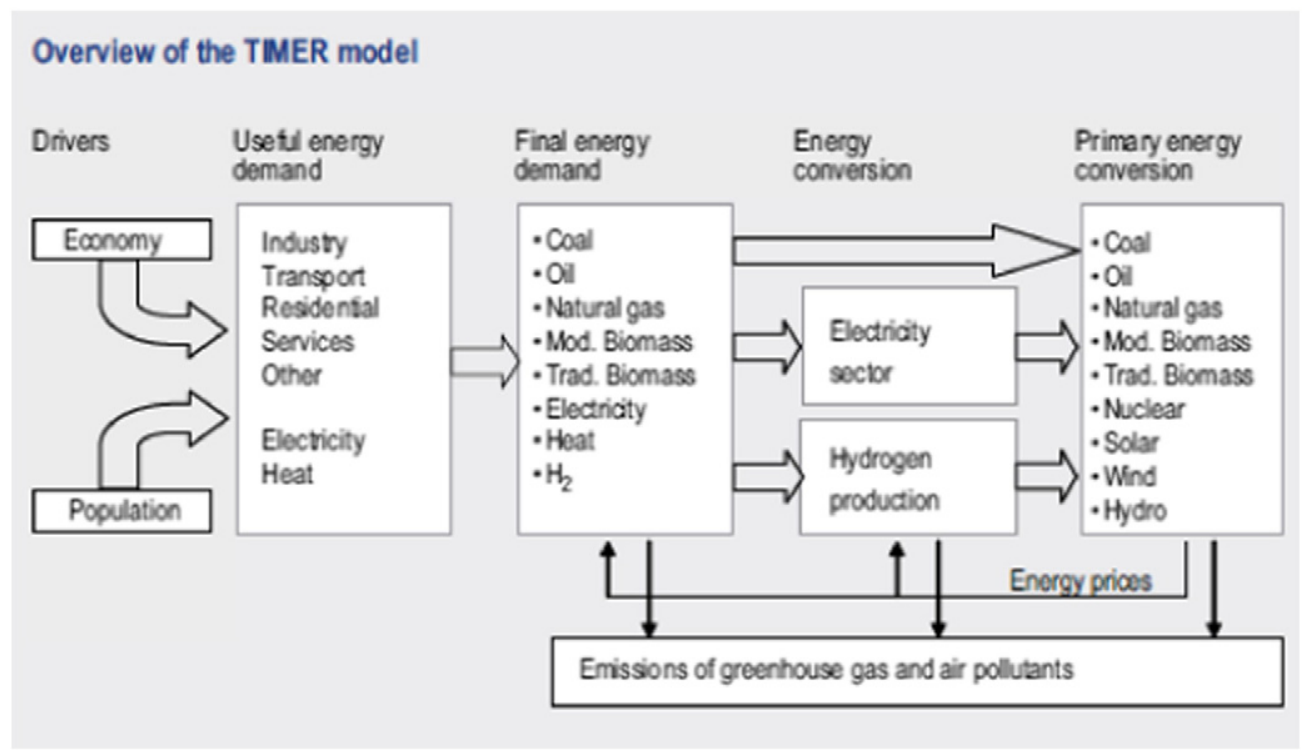

Fig. A.1. Overview of the TIMER model.

Source: Bouwman et al. (2006).

also deliver information on the potential and abatement costs of reducing emissions from the energy and land-use systems.

2. In a second step, the FAIR-SiMCaP model is used for making global emission pathways that lead to a longterm stabilization of the atmospheric greenhouse gas concentration. During this step, the FAIR model calculates the global emission reduction from the baseline scenario, assuming a cost-optimal implementation of available mitigation options over the different regions, and for the various gases and sources, using marginal abatement costs, and a constant discount rate of $5 \%$. The abatement costs

Table A.1

Main assumptions used in the TIMER energy model of IMAGE.Source: Bouwman et al. (2006).

\begin{tabular}{|c|c|c|}
\hline Category & Assumptions & References \\
\hline Fossil fuels & $\begin{array}{l}\text { Regional resources and production costs for various qualities; global trade (coal, oil and natural gas } \\
\text { are } 300,45 \text { and } 117 \text { GT respectively). Global average crude energy prices in } 2050 \text { are } 1.4,5.1 \text { and } \\
4.41995 \text { US } \$ \text { GJ for coal, oil and natural gas respectively. In } 2000 \text {, these prices are } 1.1,3.0 \text { and } \\
2.31995 \text { US } \$ \text { GJ. }\end{array}$ & Rogner (1997) \\
\hline CCS & $\begin{array}{l}\text { Regional reservoir availability and storage costs for various options (different categories of empty oil } \\
\text { and natural gas reservoirs, coal reservoirs, coal-bed methane recovery, aquifers). Total capacity } \\
\text { equals } 1500 \mathrm{GtC} \text {. Transport and storage costs range from 10-150 US\$/tC depending on the category } \\
\text { and the region. }\end{array}$ & $\begin{array}{l}\text { Hendriks et al. } \\
\text { (2002) }\end{array}$ \\
\hline $\begin{array}{l}\text { Power plant efficiency and } \\
\text { investment costs }\end{array}$ & $\begin{array}{l}\text { Power plant efficiency and investment costs for } 20 \text { types of thermal power plants using coal, oil, natural } \\
\text { gas and biomass. These include CCS defined over time. }\end{array}$ & $\begin{array}{l}\text { Hendriks et al. } \\
\text { (2004) }\end{array}$ \\
\hline Energy crops & $\begin{array}{l}\text { Potential and costs for energy crops defined by region on the basis of the maps of the previous model } \\
\text { version (IMAGE } 2.3 \text { ), including abandoned agricultural land, natural grasslands and savanna. } \\
\text { Primary biomass can be converted into liquid biofuels (for transport) and solid bioenergy (for } \\
\text { electricity). Technology development is based on learning-by-doing. Maximum potential equals } \\
230 \text { EJ in } 2050 \text { and } 600 \text { EJ in } 2100 \text {. Production costs for liquid fuels vary from } 12-16 \text { US\$ } / \text { GJ in } 2000 \\
\text { to around } 8-12 \text { US\$/GJ in } 2050 \text {, depending on the scenario. Production costs for solid fuels are } \\
\text { around } 4 \text { US\$/GJ. }\end{array}$ & Hoogwijk (2004) \\
\hline Solar/wind power & $\begin{array}{l}\text { Solar and wind power based on studies that assess global potential on the basis of } 0.5 \times 0.5 \text { degree maps. Costs } \\
\text { change over time as a result of depletion, learning-by-doing and grid penetration (declining capacity-credit } \\
\text { and excess electricity production). }\end{array}$ & Hoogwijk (2004) \\
\hline Nuclear power & $\begin{array}{l}\text { Investment costs of nuclear power based on available information in the literature (the most important } \\
\text { references are cited here). Investment costs are assumed to decrease over time. Fuel costs increase over time as } \\
\text { a result of depletion. }\end{array}$ & $\begin{array}{l}\text { MIT (2003); Sims } \\
\text { et al. (2003) }\end{array}$ \\
\hline Hydrogen & $\begin{array}{l}\text { Hydrogen modeled on the basis of production from fossil fuels, bio-energy, electricity and solar power. It } \\
\text { includes CCS. Selection on the basis of a multinomial logit model. }\end{array}$ & $\begin{array}{l}\text { van Ruijven et al. } \\
(2007)\end{array}$ \\
\hline
\end{tabular}




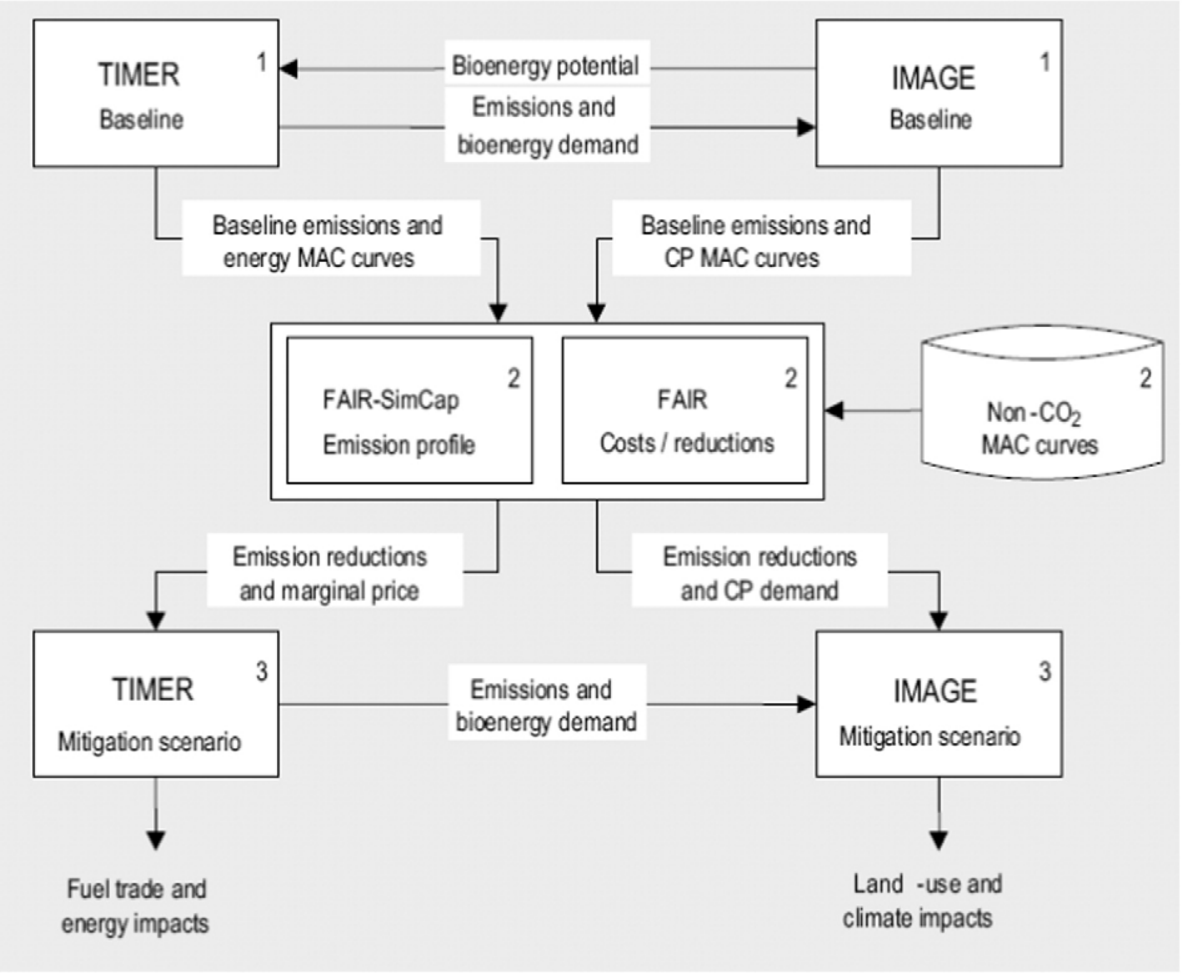

Fig. A.2. Linkage and information flows of the applied modeling framework integrating TIMER, IMAGE and FAIR. Source: Bouwman et al. (2006).

represent direct costs (therefore, they do not cover any macroeconomic feedback) and are determined from marginal reduction prices.

3. Finally, the IMAGE/TIMER model implements the changes in emission levels resulting from the mitigation action and the permit price, as determined in the previous step, to develop the final abatement scenario (emissions, land use, energy system).

\section{Appendix B. Description of the MESSAGE-Brazil model}

MESSAGE-Brazil is an adaptation of the MESSAGE ${ }^{4}$ tool that optimizes the expansion of the Brazilian power system. It is a mixed integer programming model, designed to formulate and evaluate alternative energy supply strategies, assess capacity expansion and energy production policies, given constraints such as investment limits, availability and price of fuels, environmental regulations and market penetration rates for new technologies, among others (Connolly et al., 2010; de Lucena et al., 2010; IAEA, 2006a; Keppo and Strubegger, 2010; Nogueira et al., 2014b).

\footnotetext{
${ }^{4}$ Model for Energy Supply Strategy Alternatives and their General Environmental Impacts, developed by IAASA.
}

MESSAGE-Brazil chooses the least-cost means of producing energy to meet useful demand (exogenous to the model, projected using sectorial models). The model considers the total costs for the entire energy system over the time horizon of analysis assuming perfect foresight. Thus, the model analyzes the possible substitutions among energy sources in different transformation centers from resources to final energy consumption, under restrictions of available potential (e.g., reserves and capacity for generation and transmission of electricity) and environmental impact levels (e.g., maximum GHG emissions).

The model considers eight primary sources (oil, coal, natural gas, uranium, hydropower, solar, wind and biomass). Each primary energy source is divided into a number of classes, taking into account extraction costs, quality of energy source and location of resources. This stratification allows representing nonlinear relationships between the costs of extraction and the amount of available resources. These primary sources are transformed, directly or indirectly, into final sources that satisfy the demand. The model uses over three hundred energy conversion and transport technologies to represent the production chain from primary energy, all the way to supplying the projected energy service demand.

The time horizon of analysis is 2010-2050, divided into fiveyear periods, with annual seasonality divided into four quarters and daily variations in demand and generation into five intervals that add up to $24 \mathrm{~h}$. MESSAGE-Brazil divides Brazil in three regions (S1 - south, south-east and mid-west; S2 - north 


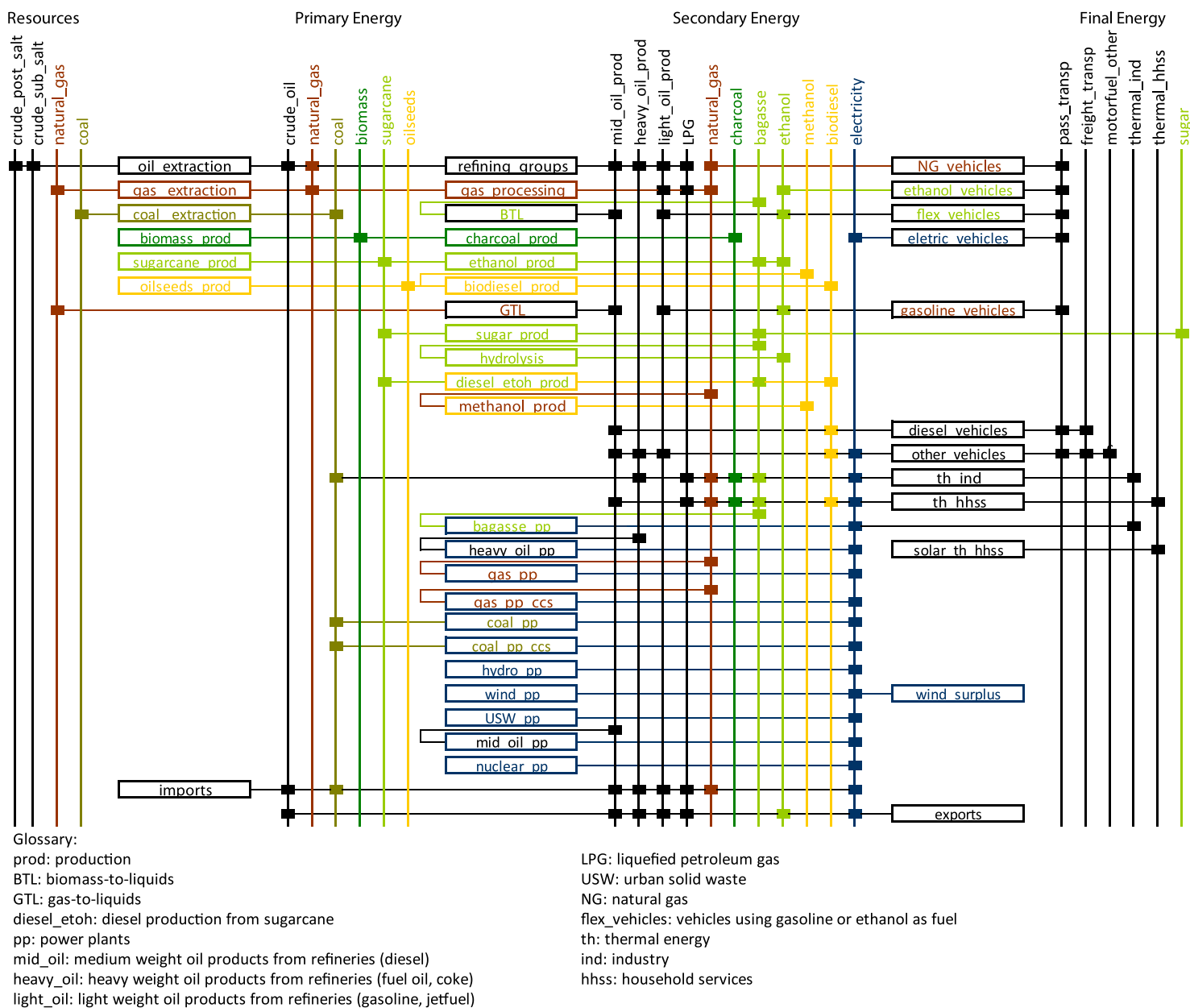

Fig. B.1. Simplified energy system structured in MESSAGE-Brazil.

and northeast; $\mathrm{R}$ - isolated regions of the Amazon). Electricity demand is represented by different load curve profiles. The power generation options include different possibilities for hydropower plants, nuclear plants, wind farms, solar facilities, thermal plants burning solid urban wastes and sugarcane bagasse, as well as conventional thermal plants fired by fuel oil, diesel oil, coal (pulverized coal - PC - and IGCC) and natural gas (open and combined cycles).

Power generation from renewable sources such as hydro, wind and solar follows a seasonal and daily profile. The seasonal output variation and capacity factors for hydroelectric plants are simulated using the historic flow series for 195 hydroelectric plants in Brazil using the MSUI (Modelo de Simulação de Usinas Individualizadas) model developed by CEPEL (Lucena et al., 2010). The seasonal variation in wind power generation was obtained from NASA (NASA, 2010), which contains average monthly wind speed data at a height of $50 \mathrm{~m}$ for the 1983-1993 period.

Thermal generation depends on the products (or byproducts) of the production chains for other energy sources. Therefore, the model is integrated so as to assure inter-sectorial consistency, considering the opportunity cost of each energy source (IAEA, 2006a).

The country's petroleum refinery park is modeled to allow partial flexibility in the runs to naphtha or distillates. Ethanol distilleries also have the flexibility to produce different products/ by-products, such as electricity (from sugar cane bagasse burning, using different technologies), second generation ethanol and sugar.

Carbon capture facilities are included in MESSAGE-Brazil both as add-on options into existing thermal power plants (retrofit option) and industrial facilities designed to be installed in new power plants (greenfield option). MESSAGE-Brazil also includes biomass power plants with CCS and CCS in ethanol distilleries.

A representation of a simplified structure of the version of MESSAGE-Brazil used in this paper is depicted in Fig. B.1.The costs and technical characteristics (efficiency and capacity factor) of the technological alternatives for electricity supply over the study horizon are presented in Table B.1. Primary energy prices are also used to establish economic competition between the technological alternatives. Learning 
Table B.1

Performance and costs characteristics of power generation technologies in MESSAGE-Brazil.

\begin{tabular}{|c|c|c|c|c|c|c|}
\hline \multirow[t]{2}{*}{ Energy option (data source) } & \multirow{2}{*}{$\begin{array}{l}\text { Current capital costs } \\
\text { (US\$ } / \mathrm{kW})\end{array}$} & \multirow[t]{2}{*}{2040 capital costs } & \multirow{2}{*}{$\begin{array}{l}\text { Current fixed } \\
\text { and O\&M costs } \\
(\mathrm{US} \$ / \mathrm{kW})\end{array}$} & \multirow[t]{2}{*}{$\begin{array}{l}2040 \text { fixed and } \\
\text { O\&M costs }\end{array}$} & \multirow{2}{*}{$\begin{array}{l}\text { Current heat rate } \\
(\%)\end{array}$} & \multirow{2}{*}{$\begin{array}{l}2040 \text { heat rate } \\
\%)\end{array}$} \\
\hline & & & & & & \\
\hline \multicolumn{7}{|l|}{$\begin{array}{l}\text { Coal power plants } \\
\text { (Borba et al., 2012; } \\
\text { Rochedo and Szklo, 2013) }\end{array}$} \\
\hline Pulverized domestic coal & 3690 & 3000 & 63 & 63 & 0.30 & 0.40 \\
\hline Pulverized imported coal & 2000 & 2000 & 60 & 60 & 0.40 & 0.40 \\
\hline Pulverized coal with CCS & 2500 & 2500 & 61 & 61 & 0.23 & 0.32 \\
\hline IGCC & 2400 & 2400 & 64 & 64 & 0.40 & 0.40 \\
\hline IGCC with CCS & 2600 & 2600 & 61 & 61 & 0.35 & 0.35 \\
\hline \multicolumn{7}{|l|}{$\begin{array}{l}\text { Natural gas power plants } \\
\text { (Borba et al., 2012; Rochedo } \\
\text { and Szklo, 2013) }\end{array}$} \\
\hline Open cycle & 650 & 650 & 4 & 4 & 0.30 & 0.30 \\
\hline Combined cycle & 1190 & 1190 & 19 & 19 & 0.50 & 0.50 \\
\hline Combined cycle with CCS & 3090 & 3090 & 31 & 31 & 0.43 & 0.43 \\
\hline Nuclear (Borba et al., 2012) & 4000 & 4000 & 130 & 130 & n.a. & n.a. \\
\hline \multicolumn{7}{|l|}{ Solar (IRENA, 2012) } \\
\hline CSP (12 h storage) & $8660-12,191$ & 5195-7315 & 147 & 85 & n.a. & n.a. \\
\hline PV & 4560 & 2736 & 300 & 300 & n.a. & n.a. \\
\hline Wind (Borba et al., 2012) & 1810 & 1547 & 175 & 158 & n.a. & n.a. \\
\hline \multicolumn{7}{|l|}{$\begin{array}{l}\text { Hydropower plants } \\
\text { (Lucena et al., 2010) }\end{array}$} \\
\hline Small hydro & 2936 & 2936 & 112 & 112 & n.a. & n.a. \\
\hline Medium hydro & 2513 & 2513 & 100 & 100 & n.a. & n.a. \\
\hline Large hydro & 2091 & 2091 & 90 & 100 & n.a. & n.a. \\
\hline \multicolumn{7}{|l|}{$\begin{array}{l}\text { Biomass power plants } \\
\text { (Borba et al., 2012) }\end{array}$} \\
\hline $\begin{array}{c}\text { With counterpressure } \\
\text { turbines }\end{array}$ & 0 & 1000 & 93 & 93 & 0.25 & 0.25 \\
\hline With CEST ${ }^{\mathrm{a}}$ - existing & 1000 & 1000 & 93 & 93 & 0.25 & 0.25 \\
\hline With CEST - new & 2712 & 2392 & 90 & 90 & 0.30 & 0.30 \\
\hline With BIG/GT ${ }^{\mathrm{b}}$ & 3596 & 2000 & 189 & 189 & 0.40 & 0.40 \\
\hline
\end{tabular}

n.a: not applicable.

${ }^{\text {a }}$ Condensing/Extraction Steam Turbine.

b Biomass Integrated Gasification/Gas Turbine.

curves are used to account for the effects of technological development on costs. Generally speaking, except for solar, conservative scenarios for cost reductions are adopted.

Up to 2015, the expansion of the electric power sector considers the power generation projects already licensed and/or under construction in the country according to data from the Brazilian Electric Power Regulatory Commission (ANEEL, 2014). After that, the model determines the least-cost system expansion options.

\section{Appendix C. Description of the AIM-Enduse model}

The AIM-Enduse model is a techno-economic and intertemporal type model with 5-year time step for mid- and longterm climate change mitigation action assessments. The model assesses future technology composition, energy consumption patterns and all GHG emissions (e.g., $\mathrm{CO}_{2}, \mathrm{CH}_{4}, \mathrm{~N}_{2} \mathrm{O}$, HFC, PFC, and $\mathrm{SF}_{6}$ ) by minimizing the total energy system cost from the year 2005 to 2100 under several constraints, such as satisfying energy-service demands and emission limits. The total energy system cost covers initial cost, operation and maintenance (O\&M) costs and fuel costs. Policy costs such as carbon tax and energy tax can be included as a part of total energy system cost. Future service demands such as the production of steel, space heating demands in the residential and commercial sector and passenger transportation are exogenously determined by using service demand projection models described in Akashi et al. (2011) and Hanaoka et al. (2009). Table C. 1 summarizes the main assumptions used in the AIMEnduse model for the various energy technologies considered.

The AIM-Enduse model covers the entire world, which is divided into 32 regions. It can calculate $\mathrm{CO}_{2}$ emissions from energy supply sectors, energy-end use sectors and nonenergy use sectors in each region. Inputs of the models, such as assumptions of future energy demand and the price of fossil fuels and technology costs, are based on statistics and service demand calculation models (Kainuma et al., 2003b). In order to simplify the model calculation, the variable for the non-energy sector was set in an exogenous manner. This can be seen in Fig. C.1 as well as the complete structure of the model.The main equations and constraints used in the AIM-Enduse model as described by Shiraki et al. (2012) are presented below. Capital letters represent exogenous variables.

\section{- Emission reduction constraint}

There are two approaches used to constrain emission reductions. The first approach is used to constrain annual 
Table C.1

Main assumptions used in the AIM-Enduse model.Source: Akashi et al. (2011) and Hanaoka et al. (2009).

\begin{tabular}{ll}
\hline Category & Assumptions \\
\hline Fossil fuels & $\begin{array}{l}\text { Regional resource costs have been set for each region. The model also considers energy subsidies in some regions, such as } \\
\text { Indonesia and Malaysia. }\end{array}$ \\
$\begin{array}{l}\text { CCS } \\
\text { Power plant efficiency and } \\
\text { investment costs }\end{array}$ & $\begin{array}{l}\text { Power plant efficiency and investment costs for } 21 \text { types of thermal power plants using coal, oil, natural gas and biomass. } \\
\text { These include CCS defined over time. }\end{array}$ \\
Solar/wind power & $\begin{array}{l}\text { Solar and wind power based on studies that assess global potential on the basis of } 1 \times 1^{\circ} \text { maps (Silva Herran, } 2012 ; \text { Silva } \\
\text { et al., } 2012 \text { ). Costs change over time as a result of depletion, learning-by-doing and grid penetration (declining capacity- } \\
\text { credit and excess electricity production). } \\
\text { Investment costs of nuclear power based on available information in the literature. Investment costs are assumed to } \\
\text { decrease over time. Fuel costs increase over time as a result of depletion. }\end{array}$ \\
& $\begin{array}{l}\text { Hydrogen modeled on the basis of production from fossil fuels, bio-energy, electricity and solar power. It includes CCS. } \\
\text { Selection on the basis of total cost through evolution. }\end{array}$ \\
&
\end{tabular}

global $\mathrm{CO}_{2}$ emissions (Eq. (C.1)). The second approach used is used to constrain cumulative emissions in the 2000-2050 period (Eq. (C.2)). The value used for cumulative $\mathrm{CO}_{2}$ emissions is $1.137 \mathrm{GtCO}_{2}$ which is based on the average from previous studies (van Vuuren and Riahi, 2011) that was calculated to stabilize radioactive forces to $2.5-3 \mathrm{~W} / \mathrm{m}^{2}$ in 2100.

$\sum_{i, g} E M S_{i, g, t} \leq \operatorname{emsmax}_{t}$

$\sum_{t=1}^{t l} \sum_{i, g} E M S_{i, g, t} \leq$ ccemsmax

where EMS is $\mathrm{CO}_{2}$ emissions, $i$ is sector, $g$ is type of gas, $t$ is time, $t$ is last year of analysis, emsmax is the maximum limit of annual $\mathrm{CO}_{2}$ emissions and ccemsmax is the maximum limit of cumulative $\mathrm{CO}_{2}$ emissions.
- $\mathrm{CO}_{2}$ emissions

$\mathrm{CO}_{2}$ emissions are calculated by multiplying the energy consumption by the emission factor (Eq. (C.3)).

$E M S_{i, g, t}=e m f_{g, k} \times E N E_{i, k, t}+e m f 0_{i, g, m, t} \times O P E_{i, m, t}$

where EMS are $\mathrm{CO}_{2}$ emissions, ENE is energy consumption, OPE is the amount of operation, $i$ is sector, $g$ is the type of gas, $t$ is time, $k$ is the type of energy, $m$ is the type of technology, emf is the emission factor of each energy and emfo is the emission factor of each operation.

- Variable renewable energy constraint

The output of renewable energies that can fluctuate depending on weather conditions (e.g., solar and wind energy), are constrained by large-scale installation (Eq. (C.4)). The AIMEnduse model treats these installation limits of variable

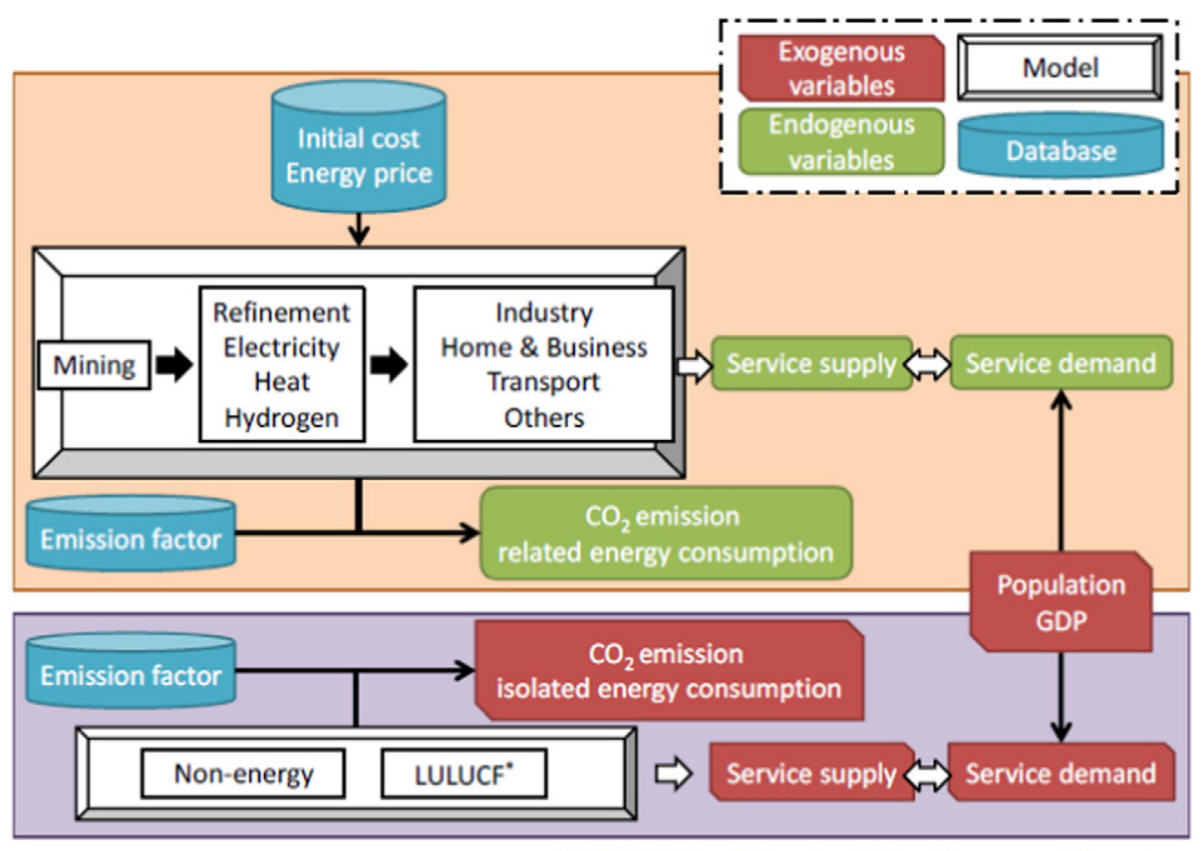

*LULUCF : Land Use, Land Use Change and Forestry

Fig. C.1. Structure of the global AIM-Enduse model. Source: Shiraki et al. (2012). 
renewable energy (VRE) as limits of the installation share of VRE. Specifically, the upper share limit of VRE without secondary battery is set to $20 \%$ of the total electricity generated and the upper share limit of VRE with and without secondary battery to $50 \%$ of the total electricity generation.

$\sum_{j e V R E} S R V_{i, j, t} \leq \lim V R E \times \sum_{j \in E L E} S R V_{i, j, t}$

where limVRE is maximal limit of installation share of VRE, $V R E$ is a subset of $j$ (service outputs from VRE devices), and $E L E$ is a subset of $j$ (service outputs from devices in the electricity sector).

- Balanced equations of service demand

The quantities of service output supplied by all devices satisfy the energy service demand (Eq. (C.5)), which is given exogenously:

$S R V_{i, j, t}=s d m_{i, j, t}$

where $S R V$ is service supply, $i$ is sector, $j$ is the type of service, $t$ is time and $s d m$ is service demand.

- Balanced equations of device input and device output The energy input of a device and the service output from the device are constrained by the energy efficiency of the various devices and operating quantity (Eqs. (C.6) and (C.7)).

$E N E_{i, k, t}=u i n_{i, k, m t} \times O P E_{i, m, t}$

$S R V_{i, j, t}=$ uout $_{i, j, m, t} \times O P E_{i, m, t}$

where ENE is the energy input, $i$ is device, $k$ is quantity, $t$ is time, uin is energy consumption per operation, $S R V$ is service output, uout is the service supply per operation and OPE is the operating quantity.

- Operating capacity constraints

The operating amount of the device must not exceed its stock net of the operating rate (Eq. (C.8)).

$O P E_{i, m, t} \leq c f_{i, m, t} \times C A P_{i, m, t}$

where OPE is operating amount of the device, CAP is Stock capacity of technology, $c f$ is the capacity factor, $i$ is sector, $m$ is the type of technology and $t$ is time.

- Objective function

The objective function is the discounted present value of the system cost during the analytical period. This includes total initial cost, total energy cost and total running cost (Eq. (C.9)).

$$
\begin{aligned}
T C= & \sum_{t} \frac{1}{(1+r)^{t-1}} \times\left\{\sum_{i, m} c f i x_{m, t} \times \operatorname{CAPf}_{i, m, t}\right. \\
& \left.+\sum_{i, k} c v a r_{i, m, t} \times E N E_{i, k, t}+\sum_{i, m} \operatorname{co\& } m_{i, m, t} \times O P E_{i, m, t}\right\}
\end{aligned}
$$

where $T C$ is the total system cost during the analytical period, $r$ is the discount rate (5\%), cfix is the initial cost per device capacity, cvar is the variable cost per energy consumption and $c o \mathcal{E} m$ is the operation and maintenance cost per quantity of operation.

\section{References}

Akashi, O., Hanaoka, T., Matsuoka, Y., et al., 2011. A projection for global $\mathrm{CO}_{2}$ emissions from the industrial sector through 2030 based on activity level and technology changes. Energy 36 (4), 1855-1867.

ANEEL, 2014. Agencia Nacional de Energia Eléctrica. Banco de Infromacao de Generacao. In Portuguese. [online]. Retrieved 29/09/2013 Available on the world wide web: http://www.aneel.gov.br/15.htm.

Beck, B., Cunha, P., Ketzer, M., et al., 2011. The current status of CCS development in Brazil. Energy Procedia 4, 6148-6151.

Borba, B.S.M.C., Lucena, A.F.P., Rathmann, R., et al., 2012. Energy-related climate change mitigation in Brazil: potential, abatement costs and associated policies. Energ Policy 49, 430-441.

Bouwman, L., Kram, T., Klein-Goldewijk, K., 2006. IMAGE 2.4: An Overview. Netherlands Environmental Assessment Agency, Bilthoven.

Calvin, K., Clarke, L., Krey, V., et al., 2012. The role of Asia in mitigating climate change: results from the Asia modeling exercise. Energy Econ. 34 (Suppl. 3), S251-S260.

Carpio, C., 2010. Energy Efficiency in Latin America and the Caribbean: Situation and Outlook. ECLAC, Economic Commission for Latin America and the Caribbean.

Centre for Climate and Energy Solutions, 2011. Common metric: Comparing countries climate pledges. Available at: http://www.c2es.org/publications/ common-metrics-comparing-countries-climate-pledges.

Connolly, D., Lund, H., Mathiesen, B.V., et al., 2010. A review of computer tools for analysing the integration of renewable energy into various energy systems. Appl. Energy 87 (4), 1059-1082.

de la Torre, A., Fajnzylber, P., Nash, J., 2009. Low-carbon, High Growth Latin American Responses to Climate Change. An Overview. The World Bank, Washington.

de Lucena, A.F.P., Szklo, A.S., Schaeffer, R., et al., 2009. The vulnerability of renewable energy to climate change in Brazil. Energ Policy 37 (3), 879-889.

de Lucena, A.F.P., Schaeffer, R., Szklo, A.S., 2010. Least-cost adaptation options for global climate change impacts on the Brazilian electric power system. Glob. Environ. Chang. 20 (2), 342-350.

de Oliveira, A., Laan, T., 2010. Lessons Learned From Brazil's Experience With Fossil-fuel Subsidies and Their Reform. The International Institute for Sustainable Development (IISD).

Den Elzen, M.G.J., Lucas, P.L., 2005. The FAIR model: a tool to analyse environmental and costs implications of regimes of future commitments. Environ. Model. Assess. 10 (2), 115-134.

den Elzen, M.G.J., Hof, A.F., Roelfsema, M., 2013. Analysing the greenhouse gas emission reductions of the mitigation action plans by non-Annex I countries by 2020. Energ Policy 56, 633-643.

Eom, J., Edmonds, J., Krey, V., et al., 2013. The impact of near-term climate policy choices on technology and emission transition pathways. Technol. Forecast. Soc. Chang. 90 (part A), 73-88.

FEEM, 2014. LIMITS project [online]. Retrieved 29/07/2014, 2014. Available on the world wide web. http://www.feem-project.net/limits/index.html.

Fresard, C., Milena, O.A., 2001. Indicadores macroeconómicos de América Latina 1990-2000. Lecturas de Economía. No 54. Inter-American Development Bank Group (Medellín).

GLOBE International, 2013. Climate Legislation Study: A Review of Climate Change Legislation in 33 countries. Third edition. Available at: http://www. globeinternational.org/images/climate-study/3rd_GLOBE_Report.pdf.

Grübler, A., Nakicenovic, N., Riahi, K., et al., 2007. Integrated assessment of uncertainties in greenhouse gas emissions and their mitigation: introduction and overview. Technol. Forecast. Soc. Chang. 74 (7), 873-886.

Hanaoka, T., Akashi, O., Hasegawa, T., et al., 2009. Global emissions and mitigation of greenhouse gases in 2020. J. Glob. Environ. Eng. 14, 15-26.

Hendriks, C., Graus, W., van Bergen, F., 2002. Global carbon dioxide storage potential and costs. Report EEP-02001 2002 Ecofys report (Utrecht).

Hendriks, C., Harmelink, M., Burges, K., Ransel, K., 2004. Power and heat productions: plant developemtn and grid losses. Report EEP-03038 2004 Ecofys report (Utrecht).

Hoogwijk, M., 2004. On the global and regional potential of renewable energy sources PhD Thesis. Utrecht University 256 p.

IADB, 2013. Climate Scope 2013 - New Frontiers for Low-carbon Energy Investment in Latin America and the Caribbean. Inter-American Development Bank and Bloomberg New Energy Finance.

IAEA, 2006a. Brazil: A Country Profile on Sustainable Energy Development. International Atomic Energy Agency.

IAEA, 2006b. Brazil: A Country Profile on Sustainable Energy Development. International Atomic Energy Agency, Austria.

IBGE, 2010. Projeção da População do Brasil por sexo e idade: 2000-2060 [online]. Retrieved 04/18, 2014. Available on the world wide web. http://www.ibge.gov.br/home/estatistica/populacao/projecao_da_populacao/ 2013/default.shtm. 
IEA, 2013. World Energy Outlook.

INPE, 2013. Projeto Prodes - Monitoramento da Floresta Amazonica Brasileira por Satelite [online]. Available on the world wide web. http://www.obt. inpe.br/prodes/index.php.

IPCC, 2007a. Intergovernmental Panel on Climate Change. Synthesis Report.

IPCC, 2007b. The Physical Science Basis. Contribution of Working Group I to the Fourth Assessment Report of the Intergovernmental Panel on Climate Change.

IPCC, 2014a. Final draft Working Group II. Volume II Regional Aspects. 5th Assessment Report - Impacts, Adaptation and Vulnerability.

IPCC, 2014b. Final draft working group III. 5th Assessment Report "Climate Change 2014: Mitigation of Climate Change".

IRENA, 2012. Renewable Energy Technologies: Cost analysis series. Volume 1: Power Sector. concentrating solar power Report, Bonn, Germany.

Johansson, D.J.A., Lucas, P.L., Weitzel, M., et al., 2014. Multi-model comparison of the economic and energy implications for China and India in an international climate regime. Mitig. Adapt. Strateg. Glob. Chang. 1-25.

Jotzo, F., 2011. Comparing the Copenhagen Emissions Targets. Crawford School Centre for Climate Economics \& Policy Paper No. 1.10. Available at: http:// ssrn.com/abstract $=1878905$.

Kainuma, M., Matsuoka, Y., Morita, T., 2003a. In: Springer (Ed.), Climate Policy Assessment: Asia-Pacific Integrated Modeling.

Kainuma, M., Matsuoka, Y., Morita, T., 2003b. Climate Policy Assessment: AsiaPacific Integrated Modeling. Springer.

Kainuma, M., Miwa, K., Ehara, T., et al., 2013. A low-carbon society: global visions, pathways, and challenges. Clim. Pol. 13 (Suppl.1), 5-21.

Keppo, I., Strubegger, M., 2010. Short term decisions for long term problems the effect of foresight on model based energy systems analysis. Energy 35 (5), 2033-2042

Kriegler, E., Tavoni, M., Aboumahboub, T., et al., 2014a. What does the $2{ }^{\circ} \mathrm{C}$ target imply for a global climate agreement in 2020? The LIMITS study on Durban Platform scenarios. Clim. Chang. Econ. 04 (04).

Kriegler, E., Riahi, K., Bauer, N., et al., 2014b. Making or breaking climate targets: the AMPERE study on staged accession scenarios for climate policy. Technol. Forecast. Soc. Chang. 90 (part A), 24-44.

La Rovere, E.L., Burle Dubeux, C., Pereira Jr., A.O., et al., 2013. Brazil beyond 2020: from deforestation to the energy challenge. Clim. Pol. 13 (Suppl.1), 70-86.

Lucas, P.L., Shukla, P.R., Chen, W., et al., 2013. Implications of the international reduction pledges on long-term energy system changes and costs in China and India. Energ Policy 63, 1032-1041.

Lucena, A.F.P., Schaeffer, R., Szklo, A.S., et al., 2010. Estudo de vulnerabilidade do Sistema Hidroeléctrico as Mudancas Climáticas. Projeto PNUD BRA/05/G31 (In Portuguese).

Malagueta, D., Szklo, A., Borba, B.S.M.C., et al., 2013. Assessing incentive policies for integrating centralized solar power generation in the Brazilian electric power system. Energ Policy 59, 198-212.

Ministry of Environment Brazil, 2007. National Plan of Climate Change. Available at: http://www.mma.gov.br/publicacoes/clima/category/70-mudancas-doclima.

Ministry of Mines and Energy Brazil, 2010. Decennial Plan of Energy Expansion 2019. Available at: http://www.epe.gov.br/pdee/forms/epeestudo.aspx.

Ministry of Mines, Energy Brazil, 2012. Decennial Plan of Energy Expansion 2021. Available at: http://www.epe.gov.br/pdee/forms/epeestudo.aspx.

Ministry of Mines, Energy Brazil, 2013. Decennial Plan of Energy 2021. Available at: http://mme.gov.br/mme/arquivos/pde_2019/PDE_2021/ PDE_2021.

MIT, 2003. The future of nuclear power - an interdisciplinary MIT study. Massachusetts Institute of Technology, Cambridge, pp. 1-180.

Nachmany, M., Fankhauser, S., Townshend, T., Collins, M., Landesman, T., Matthews, A., Pavese, C., Rietig, K., Schleifer, P., Setzer, J., 2001. The GLOBE Climate Legislation Study: A Review of Climate Change Legislation in 66 countries. London School of Economics. Federal Law No. 10294/2001 National Conservation and Rational Energy Use Policy(Legislative) Fourth Edition.

Nachmany, M., Fankhauser, S., Townshend, T., Collins, M., Landesman, T., Matthews, A., Pavese, C., Rietig, K., Schleifer, P., Setzer, J., 2005. The GLOBE Climate Legislation Study: A Review of Climate Change Legislation in 66 countries. Mandatory Biodiesel Requirement - Federal Law No. 11097/2005 (amended in 2009 and 2010) (Legislative) Fourth Edition. GLOBE International and the Grantham Research Institute, London School of Economics, London.

Nachmany, M., Fankhauser, S., Townshend, T., Collins, M., Landesman, T., Matthews, A., Pavese, C., Rietig, K., Schleifer, P., Setzer, J., 2008. The GLOBE Climate Legislation Study: A Review of Climate Change Legislation in 66 countries. National Plan for Climate Change - Law No. 12187/2009, Decree No. 7390/2010 (Executive) Fourth Edition. GLOBE International and the Grantham Research Institute, London School of Economics, London.
Nachmany, M., Fankhauser, S., Townshend, T., Collins, M., Landesman, T., Matthews, A., Pavese, C., Rietig, K., Schleifer, P., Setzer, J., 2012. The GLOBE Climate Legislation Study: A Review of Climate Change Legislation in 66 countries. Law No. 10438/2002 - Programme of Incentives for Alternative Electricity Sources (PROINFA) (Legislative) Fourth Edition. GLOBE International and the Grantham Research Institute, London School of Economics, London.

Nachmany, M., Fankhauser, S., Townshend, T., et al., 2014. The GLOBE Climate Legislation Study: A Review of Climate Change Legislation in 66 Countries. Fourth edition. GLOBE International and the Grantham Research Institute, London School of Economics, London.

NASA, 2010. National Aeronautics and Space Administration. [online]. Retrieved 20/11/2010, 2010. Available on the world wide web. https://eosweb.larc. nasa.gov/sse/.

Nogueira, L.P.P., Frossard Pereira de Lucena, A., Rathmann, R., et al., 2014a. Will thermal power plants with CCS play a role in Brazil's future electric power generation? Int. J. Greenhouse Gas Control 24 (0), 115-123.

Nogueira, L.P.P., Frossard Pereira de Lucena, A., Rathmann, R., et al., 2014b. Will thermal power plants with CCS play a role in Brazil's future electric power generation? Int. J. Greenhouse Gas Control 24 (0), 115-123.

OECD, 2012. OECD Environmental Outlook to 2050: The Consequences of Inaction. Organisation for Economic Cooperation and Development, OECD Publishing.

Riahi, K., Kriegler, E., Johnson, N., et al., 2013. Locked into Copenhagen pledges implications of short-term emission targets for the cost and feasibility of long-term climate goals. Technol. Forecast. Soc. Chang. 90 (part A), 8-23.

Rochedo, P.R.R., Szklo, A., 2013. Economic analysis under uncertainty of coal fired capture-ready power plants. Int. J. Greenhouse Gas Control 12, 44-55.

Rogner, H.H., 1997. An assessment of World Hydrocarbon Resources. Annu. Rev. Energy Environ. 22, 217-262.

Saraiva, T.A., Szklo, A., Lucena, A.F.P., et al., 2014. Forecasting Brazil's crude oil production using a multi-Hubbert model variant. Fuel 115, 24-31.

Schaeffer, R., Szklo, A., Gouvello, C., 2010. Low Carbon Emissions Scenarios in Brazil. The World Bank Group (Synthesis Report).

Schaeffer, R., Szklo, A., Frossard Pereira de Lucena, A., et al., 2013a. The vulnerable Amazon: the impact of climate change on the untapped potential of hydropower systems. IEEE Power Energ. Mag. 11 (3), 22-31.

Schaeffer, M., Gohar, L., Kriegler, E., et al., 2013b. Mid- and long-term climate projections for fragmented and delayed-action scenarios. Technol. Forecast. Soc. Chang. 90 (part A), 257-268.

Schneider, S.H., 1997. Integrated assessment of global climate change: transparent rational tool for policy making or opaque screen hiding value-laden assumptions? Environ. Model. Assess. 2, 229-249.

Sheinbaum, C., Ruíz, B.J., Ozawa, L., 2011. Energy consumption and related $\mathrm{CO}_{2}$ emissions in five Latin American countries: changes from 1990 to 2006 and perspectives. Energy 36 (6), 3629-3638.

Shiraki, H., Ashina, S., Akashi, O., et al., 2012. The Impact of Nuclear Policy Changes on Climate Change Mitigation Policy in Asia (Kyoto).

Silva, D., Ashina, S., Fujino, J., 2012. Prelimnary assessment of biomass energy potential in Asia using geo-referenced data. 35th IAEE International Conference Conference proceedings 24-27 June Perth, Australia.

Silva Herran, D., 2012. Renewable Energy potential model - Manual (Solar, Wind) version of 2012/01/16. http://www.nies.go.jp/aim/datalibrary.htm Report 2012.

Sims, R.E.H., Rogner, H.-H., Gregory, K., 2003. Carbon emission and mitigation cost comparisons between fossil fuel, nuclear and renewable energy resources for electricity generation. Energy Policy 31 (13), 1315-1326.

Tolmasquim, M.T., 2012. Perspectivas e planejamento do setor energético no Brasil. Estudos Avançados 26 (74), 247-260.

UN, 2008. World Population Prospects, The 2008 Revision.

UN, 2009. World Population Prospects: The 2008 Revision. Population Division of the Department of Economic and Social Affairs of the United Nations Secretariat.

UNEP, 2010. The Emissions Gap Report - Are the Copenhaguen Pledges sufficient to limit global warming to 2 or 1.5 degrees celsius? A prelimnary assessment. Available at: http://www.unep.org/publications/ ebooks/emissionsgapreport/pdfs/GAP_REPORT_SUNDAY_SINGLES_LOWRES. pdf.

van Ruijven, B.J., van Vuuren, D.P., van Vliet, J., et al., 2012. Implications of greenhouse gas emission mitigation scenarios for the main Asian regions. Energy Econ. 34 (Suppl. 3), S459-S469.

van Vuuren, D.P., Riahi, K., 2011. The relationship between short-term emissions and long-term concentration targets. Clim. Chang. 104 (3-4), 793-801.

Van Vuuren, D.P., Den Elzen, M.G.J., Lucas, P.L., et al., 2007. Stabilizing greenhouse gas concentrations at low levels: an assessment of reduction strategies and costs. Clim. Chang. 81 (2), 119-159.

van Ruijven, B., van Vuuren, D.P., de Vries, B., 2007. The potential role of hydrogen in energy systems with and without climate policy. Int. J. Hydrog. Energy 32 (12), 1655-1672. 
Vergara, W., Alatorre, C., Alves, L., 2013a. Rethinking our Energy Future - A White Paper on Renewable Energy for the 3GFLAC Regional Forum. InterAmerican Development Bank.

Vergara, W., Rios, R.R., Galindo, L.M., et al., 2013b. The Climate and Development Challenge for Latin America and the Caribbean: Options for Climate-resilient, Low-carbon Development No. 978-1-59782-165-0 (IADB).

Viola, E., Franchini, M., 2011. A mudanca climática em 2011: Governanca estagnada e o novo perfil do Brasil. Textos CINDES n 25. CINDES - Centro de Estudos de Integracao e Desenvolvimento.

World Bank, 2010. Brasil: País de Baixo Carbono. Estudo de caso. ESMAP Energy Sector Management Assistance Program. Available here. http:// www.esmap.org/sites/esmap.org/files/2011000172BRAbra001_LowRes.pdf.

World Bank, 2012. GDP Growth Data [online]. Retrieved 04/16, 2013. Available on the world wide web. http://data.worldbank.org/indicator.

Sara Herreras Martínez holds a degree in Energy Science and a degree in Chemistry. She works as a researcher as part of the IMAGE modeling team at the University of Utrecht (The Netherlands). She has major interest on the role of developing countries on climate change mitigation. Previously she worked at the consultancy Climate Focus giving advice on climate policies and climate finance.

Alexandre Koberle is a PhD researcher in the Energy Planning Program at COPPE/UFRJ in Brazil and an associate researcher of The Netherlands Environmental Assessment Agency (PBL). He holds a MSc in Environmental and Resource Management from Vrije Universiteit Amsterdam and a BS in Plant Biology and Ecology from the University of California, Davis. Alexandre is working on solar energy modeling at PBL and on renewable energy issues in Latin America. He is the author of a report on Guatemala's energy expansion plans for International Rivers. In the past he also worked in the private sector in California.

Pedro Rochedo is a doctorate student at the Energy Planning Program of the Universidade Federal do Rio de Janeiro. He received a chemical engineering degree in 2009 and a master's degree in Energy Planning in 2011. In 2013, he participated in the Young Scientist Summer Program at the International Institute of Applied System Analysis (IIASA), in Austria. In the same year, he also won the national Vale-Capes award for best Master's Dissertation on the category Greenhouse Gas Emissions Reduction.
Roberto Schaeffer is an Associate Professor of Energy Economics at the Energy Planning Program of the Universidade Federal do Rio de Janeiro. He holds a PhD in Energy Management and Policy from the University of Pennsylvania. Previously he was a Visiting Professor at the Centre for Energy and the Environment, and a Lecturer at the Wharton School, both at the University of Pennsylvania. In 2008 he held a Chair of Visiting Professor in Brazilian Studies in Canada, lecturing in five different Canadian universities with the support of the Ministry of Foreign Affairs and International Trade of Canada.

Andre Lucena is an economist, with a master and doctorate in Energy Planning. $\mathrm{He}$ is currently an Associate Professor at the Energy Planning Program of the Federal University of Rio de Janeiro, Brazil.

Alexandre Szklo is a Professor at the Energy Program of the Graduate School of Engineering in the Federal University of Rio de Janeiro. He is a Chemical Engineer and PhD in Energy Technologies and Economics. Alexandre is the author of 69 papers published in scientific refereed journals, 129 presentations at conferences and advisor of $69 \mathrm{PhD}$ thesis and MSc dissertations. Alexandre makes up the core of Advisors on Innovation and Technology for the Brazilian Governmental Agency CNPq.

Shuichi Ashina is a Senior Researcher in the Sustainable Social System Section, Centre for Social and Environmental Systems Research, NIES from the year 2006. His research focuses on the field of EnergyEconomy-Environmental system modeling and its application to low carbon societies. He also conducts a research on a sub-national scale energy system design with renewables. He received his B.S., M.S. and PhD degrees in mechanical and system engineering from Tohoku University.

Detlef P. van Vuuren is a senior researcher at PBL Netherlands Environmental Assessment Agency working on integrated assessment of global environmental change problems. He also holds a position as a professor at Utrecht University on the same topic. He has been the (convening) lead author on several international assessments including IPCC, UNEP's Global Environmental Outlook and the Millennium Ecosystem Assessment. He has published over 150 articles in the peer reviewed scientific literature. 